US Army Corps of Engineers $S_{\circledast}$ Engineer Research and Development Center

Strategic Environmental Research and Development Program (SERDP)

\title{
Identifying Military Impacts on Archaeological Deposits Based on Differences in Soil Organic Carbon and Chemical Elements at Soil Horizon Interfaces
}

Final Report on SERDP Project RC 1698

Dick L. Gebhart, H. Allen Torbert, Michael L. Hargrave,

March 2012

Ryan R. Busby, and Antonio J. Palazzo 



\section{Identifying Military Impacts on Archaeological Deposits Based on Differences in Soil Organic Carbon and Chemical Elements at Soil Horizon Interfaces}

Final Report on SERDP Project RC 1698

Dick L. Gebhart, Michael L. Hargrave, and Ryan R. Busby

Construction Engineering Research Laboratory

U.S. Army Engineer Research and Development Center

2902 Newmark Drive

Champaign, IL 61822

H. Allen Torbert

National Soil Dynamics Laboratory

Agricultural Research Service

US Department of Agriculture

411 S. Donahue Drive

Auburn, AL 36832

Antonio J. Palazzo

Cold Regions Research and Engineering Laboratory

U.S. Army Engineer Research and Development Center

72 Lyme Road

Hanover, New Hampshire 03755-1290

Final report

Approved for public release; distribution is unlimited.

Prepared for Strategic Environmental Research and Development Program (SERDP)

901 North Stuart St., Suite 303

Arlington, VA 22203

Under SERDP Project RC 1698 


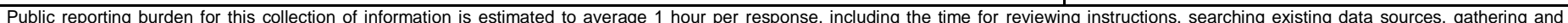

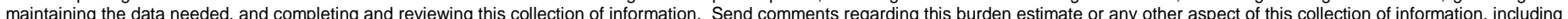

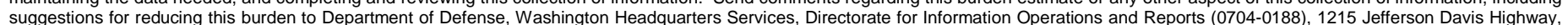

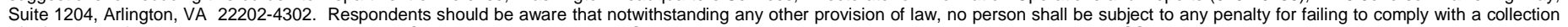
of information if it does not display a currently valid OMB control number. PLEASE DO NOT RETURN YOUR FORM TO THE ABOVE ADDRESS.

\begin{tabular}{l|l} 
1. REPORT DATE (DD-MM-YYYY) & 2. REPORT TYPE
\end{tabular}

March 2012

Final

\section{TITLE AND SUBTITLE}

Identifying Military Impacts on Archaeological Deposits Based on Differences in

Soil Organic Carbon and Chemical Elements at Soil Horizon Interfaces

3. DATES COVERED (From - To)

5a. CONTRACT NUMBER

5b. GRANT NUMBER

5c. PROGRAM ELEMENT NUMBER

6. AUTHOR(S)

Dick L. Gebhart, H. Allen Torbert, Michael L. Hargrave, Ryan R. Busby, and Antonio J. Palazzo

5d. PROJECT NUMBER

SERDP RC 1698

5e. TASK NUMBER

5f. WORK UNIT NUMBER

8. PERFORMING ORGANIZATION REPORT NUMBER

U.S. Army Engineer Research and Development Center

Construction Engineering Research Laboratory

P.O. Box 9005

Champaign, IL 61826-9005

9. SPONSORING I MONITORING AGENCY NAME(S) AND ADDRESS(ES)

Strategic Environmental Research and Development Program (SERDP)

901 North Stuart St., Suite 303

Arlington, VA 22203

ERDC/CERL TR-12-5

10. SPONSOR/MONITOR'S ACRONYM(S)

11. SPONSOR/MONITOR'S REPORT NUMBER(S)

Final Report RC 1698

\section{DISTRIBUTION I AVAILABILITY STATEMENT}

Approved for public release; distribution is unlimited.

\section{SUPPLEMENTARY NOTES}

\section{ABSTRACT}

Military training is often assumed to negatively impact archaeological resources, but methodologies to estimate or infer damage to these resources are expensive and time consuming. Cultural resources managers require a technique allowing them to estimate past and current impacts of training on archaeological site condition and determine if the site is capable of supporting future training activities. The technical objectives of this research were (1) to demonstrate that naturally occurring and culturally induced stratigraphic differences in a suite of soil parameters, such as soil organic carbon and chemical elements, at the interface of near-surface soil horizons can be disrupted to varying degrees by military training and other (e.g., agricultural) human actions and (2) to use this predictable stratification as the basis for an innovative, low-cost, widely applicable, reliable method to identify the onset and quantify the extent of adverse impacts to archaeological deposits that are associated with military training.

\section{SUBJECT TERMS}

archaeology, land disturbance, military training impacts, soil sampling,

\section{SECURITY CLASSIFICATION OF:}

\section{a. REPORT}

Unclassified b. ABSTRACT

Unclassified
17. LIMITATION OF ABSTRACT
18. NUMBER OF PAGES

56 19a. NAME OF RESPONSIBLE PERSON

19b. TELEPHONE NUMBER (include area code) 


\section{TABLE OF CONTENTS}

REPORT DOCUMENTATION PAGE ii

LIST OF TABLES IV

LIST OF FIGURES $\quad$ v

ABBREVIATIONS AND ACRONYMS vi

ACKNOWLEDGMENTS vi

EXECUTIVE SUMMARY vii

1. OBJECTIVE 1

2. BACKGROUND 2

3. MATERIALS AND METHODS 8

3.1 Archaeology Habitation Sites, Fort Benning, GA 10

3.2 Archaeology Habitation Sites, Fort Riley, KS 13

3.3 Archaeology Habitation Sites, Yakima Training Center, WA 15

4. RESULTS AND DISCUSSION 18

4.1 Vertical Trends and Indicators 18

4.2 Soil Organic Carbon 18

$\begin{array}{ll}4.3 \text { Extractable Nickel } & 22\end{array}$

$\begin{array}{ll}4.4 \text { Soil pH } & 24\end{array}$

4.5 Extractable Calcium, Magnesium, and Manganese 26

4.6 Total Phosphorus 31

4.7 Ratios 32

4.7.1 Top-to-Total Ratio 33

4.7.2 Total-to-Soluble Ratio 34

4.7.3 Leachable-to-Nonleachable Ratio 35

4.7.4 Soil Variables Removed From Consideration 36

4.8 Dose/Response Transect, Fort Riley, KS 36

5. CONCLUSIONS AND IMPLICATIONS FOR FUTURE RESEARCH 41

LITERATURE CITED $\quad 45$ 


\section{LIST OF FIGURES}

Figure 1. A conceptualized example of a soil profile illustrating changes in vertical stratification of soil horizons due to disturbance. Intact archaeological deposits often occur immediately below the A/B horizon interface.

Figure 2. Percent carbon with depth from disturbed (D) and undisturbed (U) archaeological (A) and non-archaeological (N) treatment groups.

Figure 3. Extractable nickel concentration with depth from disturbed (D) and undisturbed (U) archaeological (A) and non-archaeological (N) treatment groups. 24 Figure 4. Soil $\mathrm{pH}$ with depth from disturbed (D) and undisturbed (U) archaeological (A) and non-archaeological (N) treatment groups.

Figure 5. Extractable calcium concentration with depth from disturbed (D) and undisturbed (U) archaeological (A) and non-archaeological (N) treatment groups. 30 Figure 6. Extractable magnesium concentration with depth from disturbed (D) and undisturbed (U) archaeological (A) and non-archaeological (N) treatment groups.

Figure 7. Extractable manganese concentration with depth from disturbed (D) and undisturbed (U) archaeological (A) and non-archaeological (N) treatment groups.

Figure 8. Total phosphorus concentration with depth from disturbed (D) and undisturbed (U) archaeological (A) and non-archaeological (N) treatment groups.

Figure 9. Ratio of total phosphorus and total sulfur concentrations in the upper $10 \mathrm{~cm}$ to the respective concentrations in the entire $50 \mathrm{~cm}$ soil profile.

Figure 10. Ratio of total-to-soluble calcium and potassium concentrations at Fort Riley, KS, in the 0-10 cm depth increment.

Figure 11. Ratio of leachable (potassium and sulfur) to nonleachable (total iron) element concentrations at Fort Benning, GA, and Fort Riley, KS, in the $0-10 \mathrm{~cm}$ depth increment.

Figure 12. Total phosphorus depth distribution in a Wymore soil profile as a function of increasing numbers of passes by an M1A1 tank.

Figure 13. Extractable calcium depth distribution in a Wymore soil profile as a function of increasing numbers of passes by an M1A1 tank.

Figure 14. Extractable manganese depth distribution in a Wymore soil profile as a function of increasing numbers of passes by an M1A1 tank.

Figure 15. Soil $\mathrm{pH}$ depth distribution in a Wymore soil profile as a function of increasing numbers of passes by an M1A1 tank.

Figure 16. Extractable magnesium depth distribution in a Wymore soil profile as a function of increasing numbers of passes by an M1A1 tank.

Figure 17. Extractable nickel depth distribution in a Wymore soil profile as a function of increasing numbers of passes by an M1A1 tank.

\section{LIST OF TABLES}

Table 1. Means and (standard errors) of treatment $x$ depth interaction effects for soil variables with a significant interaction term using ANOVA with an 
alpha $=0.05$

Table 2. Percent carbon with depth from disturbed (D) and undisturbed (U) archaeological (A) and adjacent non-archaeological (N) site locations at

Fort Riley, KS and Fort Benning, GA.

Table 3. Extractable nickel concentration (mg/kg) with depth from disturbed

(D) and undisturbed (U) archaeological (A) and adjacent non-archaeological

(N) site locations at Fort Riley, KS and Fort Benning, GA.

Table 4. Soil $\mathrm{pH}$ with depth from disturbed (D) and undisturbed (U)

archaeological (A) and adjacent non-archaeological (N) site locations at

Fort Riley, KS and Fort Benning, GA.

Table 5. Extractable calcium concentration $(\mathrm{mg} / \mathrm{kg})$ with depth from disturbed (D) and undisturbed (U) archaeological (A) and adjacent

non-archaeological $(\mathrm{N})$ site locations at Fort Riley, KS and Fort Benning, GA.

27

Table 6. Extractable magnesium concentration $(\mathrm{mg} / \mathrm{kg})$ with depth from

disturbed (D) and undisturbed (U) archaeological and adjacent

non-archaeological (N) site locations at Fort Riley, KS and Fort Benning, GA. $\quad 28$

Table 7. Extractable manganese concentration $(\mathrm{mg} / \mathrm{kg})$ with depth from

disturbed (D) and undisturbed (U) archaeological and adjacent

non-archaeological (N) site locations at Fort Riley, KS and Fort Benning, GA. 


\section{ABBREVIATIONS AND ACRONYMS}

$\begin{array}{ll}\mathrm{Al} & \text { Aluminum } \\ \mathrm{B} & \text { Boron } \\ \mathrm{C} & \text { Carbon } \\ \mathrm{Ca} & \text { Calcium } \\ \mathrm{Cd} & \text { Cadmium } \\ \mathrm{Cr} & \text { Chromium } \\ \mathrm{Cu} & \text { Copper } \\ \mathrm{EPA} & \text { Environmental Protection Agency } \\ \mathrm{Fe} & \text { Iron } \\ \mathrm{GPS} & \text { Global Positioning System } \\ \mathrm{K} & \text { Potassium } \\ \mathrm{Mg} & \text { Magnesium } \\ \mathrm{Mn} & \text { Manganese } \\ \mathrm{Mo} & \text { Molybdenum } \\ \mathrm{N} & \text { Nitrogen } \\ \mathrm{Na} & \text { Sodium } \\ \mathrm{Ni} & \text { Nickel } \\ \mathrm{NRHP} & \text { National Register of Historic Places } \\ \mathrm{P} & \text { Phosphorus } \\ \mathrm{Pb} & \text { Lead } \\ \mathrm{S} & \text { Sulfur } \\ \mathrm{SERDP} & \text { Strategic Environmental Research and Development Program } \\ \text { SOC } & \text { Soil Organic Carbon } \\ \text { USDA-NRCS } & \text { United States Department of Agriculture, Natural Resources Conservation Service } \\ \text { USGS } & \text { United States Geologic Survey } \\ \text { Zn } & \text { Zinc }\end{array}$

\section{ACKNOWLEDGMENTS}

The authors wish to express sincere appreciation to the Cultural Resources Management Staffs at Fort Benning, Georgia, Fort Riley, Kansas, and Yakima Training Center, Washington, for assistance in site selection. The authors also wish to thank the Strategic Environmental Research and Development Program (SERDP) for providing the funding that supported this work. Appreciation for technical assistance is extended to Dr. Jeffery Marqusee, Executive Director, and to Dr. John Hall, Resource Conservation and Climate Change Program Manager. Appreciation is also expressed to the staff of HydroGeoLogic, Inc., for their administrative assistance.

The work was performed by the Ecological Processes Branch (CN-N) of the Installations Division (CF), U.S. Army Engineer Research and Development Center, Construction Engineering Research Laboratory (ERDC-CERL). At the time of publication, William D. Meyer was Chief, CEERD-CN-N; Dr. John T. Bandy was Chief, CEERD-CN; and Dr. Alan B. Anderson (CEERDCV-T) was the Technical Director for Military Ranges and Lands. The Deputy Director of ERDC-CERL was Dr. Kirankumar Topudurti and the Director was Dr. Ilker Adiguzel.

COL Kevin J. Wilson was the Commander and Executive Director of ERDC, and Dr. Jeffery P. Holland was the Director. 


\section{EXECUTIVE SUMMARY}

Objectives: Military training is often assumed to negatively impact archaeological resources, but methodologies to estimate or infer damage to these resources are expensive and time consuming. Cultural resources managers require a technique allowing them to estimate past and current impacts of training on archaeological site condition and determine if the site is capable of supporting future training activities. The technical objectives of this research were (1) to demonstrate that naturally occurring and culturally induced stratigraphic differences in a suite of soil parameters, such as soil organic carbon and chemical elements, at the interface of near-surface soil horizons can be disrupted to varying degrees by military training and other (e.g., agricultural) human actions, and (2) to use this predictable stratification as the basis for an innovative, lowcost, widely applicable, reliable method to identify the onset and quantify the extent of adverse impacts to archaeological deposits that are associated with military training.

Technical Approach: Using changes in the distribution of selected soil chemical variables, this research applied simple soil coring and laboratory analyses to estimate severity and depth of disturbance. At Fort Benning, GA, and Fort Riley, KS, soil cores were collected from sites representing disturbed and undisturbed archaeological and non-archaeological treatment groups. Each core was subdivided into $5 \mathrm{~cm}$ increments, dried at $55^{\circ} \mathrm{C}$, processed to pass through a $0.15 \mathrm{~mm}$ mesh screen, and analyzed for total nitrogen, organic carbon, $\mathrm{pH}$, lime buffer capacity, cation exchange capacity, extractable aluminum, boron, calcium, cadmium, chromium, copper, iron, potassium, magnesium, manganese, molybdenum, sodium, nickel, phosphorus, lead, and zinc and total phosphorus, potassium, calcium, magnesium, sulfur, manganese, iron, aluminum, boron, copper, zinc, sodium, nickel, lead, and chromium. Data from each archaeological and nonarchaeological site within each installation were combined for statistical analyses.

Results: Significant treatment group by depth interactions for carbon, $\mathrm{pH}$, total phosphorus, and extractable calcium, magnesium, manganese, and nickel indicated divergence in distribution of soil variables with depth that could be attributed to physical disturbance (mixing, inversion, or burial). Soil carbon, $\mathrm{pH}$, calcium, magnesium, manganese, nickel, and phosphorus values were different for disturbed treatment groups to depths ranging from 10 to $30 \mathrm{~cm}$ when compared with undisturbed treatment groups, suggesting these variables may have utility in estimating severity and depth of disturbance. This was especially evident when data were used in ratios or combinations with other soil variables that would serve to normalize changes in absolute soil concentrations, thereby providing a more standardized measure of soil mixing across multiple soil types.

The recognition that ratios or combinations of soil variables might be more stable indicators of disturbance across wide geographic and edaphic ranges than single variables led to the development of several small-scale validation tests involving the concept of top-to-total ratios, total-tosoluble ratios, and leachable-to-nonleachable elemental ratios. Significant top-to-total, total-tosoluble, and leachable-to-nonleachable ratios were observed for total phosphorus and total sulfur, calcium and potassium, and potassium:iron/sulfur:iron, respectively, indicating that soil mixing to depths between 10 to $20 \mathrm{~cm}$ had occurred and that these ratios may hold promise as measures of severity and depth of soil disturbance. Top-to-total, total-to-soluble, and leachable-tononleachable ratios were only developed on small subsets of data from each installation as proof 
of concept exercises, but preliminary analyses indicate these types of derived ratios may be promising areas for continued research.

Benefits: The use of soil pH, soil organic carbon, extractable nickel, calcium, magnesium, and manganese concentrations as indicators of both severity and depth of disturbance may be enhanced when used in combination or ratio with any number of other soil variables, including organic carbon, zinc, chromium, lead, etc., and when used in combination with other archaeological surveying tools to locate archaeological sites. Additional site analyses are needed to better verify the use of these and other soil indicators for these surveys. 


\section{OBJECTIVES}

Research was proposed to address directly three of the four topics included in a 2009 SERDP Statement of Need, "Understanding the Impacts of Military Activities on Archaeological Resources.” Specifically, our research addressed the following topics: (1) identify an innovative method to measure the impact of military-unique training disturbances on archaeological resources; (2) predict the intensity of adverse impacts based on soil type, slope, vegetation, moisture, and type of military activity; and (3) identify acceptable thresholds for training. The innovative method to quantify adverse impacts to archaeological deposits using vertical patterns in soil organic carbon (SOC), macroaggregates, and chemical elements proposed was expected to identify many situations where military training has a negligible adverse impact on archaeological resources, thereby lessening restrictions on military training. Since many archaeological features such as burials, house floors, and storage pits are intrusive into the B horizon of soils, any disturbance which impacts the A/B horizon interface would likely impact the upper portions of archaeological features contained therein. The research discussed here operates under the hypothesis that these $\mathrm{A} / \mathrm{B}$ soil horizon interfaces are a threshold indicator of impending damage from training pressures to the integrity of intact archaeological deposits. Irrespective of training type or intensity, these interfaces serve as an integrator that can be used to (1) estimate past and current impacts of training on archaeological site condition and (2) determine if the site is capable of supporting future training activities.

The technical objectives of this research were (1) to demonstrate that naturally occurring and culturally induced stratigraphic differences in a suite of soil parameters such as SOC and chemical elements (e.g., P, Mg, Ca, Zn, Cu, Pb) at the interface of near-surface soil horizons can be disrupted to varying degrees by military training and other (e.g., agricultural) human actions and (2) to use this predictable stratification as the basis for an innovative, low-cost, widely applicable, reliable method to identify the onset and quantify the extent of adverse impacts to archaeological deposits that are associated with military training. 


\section{BACKGROUND}

Archaeological sites consist of artifacts and features (constructed facilities such as houses, hearths, and storage pits) that occur in soil and/or sediment matrices. Sites are the end results of multiple, diverse episodes of human behavior, and archaeologists use the patterning detected within sites as a basis for inferences about the nature and chronology of past behavior. Thoroughly investigated sites almost invariably exhibit evidence for temporal variation in the number of residents, the type of activities conducted there, and the nature of organic and inorganic materials that comprise the archaeological deposits (Hargrave et al. 1983; Hargrave et al. 1998; Jefferies and Butler 1982; Schiffer 1983, 1987). A site's scientific and cultural value and eligibility for the National Register of Historic Places (NRHP) is closely related to its depositional integrity--the degree to which the three-dimensional relationships between artifacts, features, soils and sediments are similar to those that existed when/as the site was formed. Depositional integrity is generally evaluated by means of careful hand excavation, which is time consuming, expensive, and itself destructive. Modern human activities (e.g., agriculture, infrastructure development, and military training) and natural processes can alter or destroy the spatial relationships and associations among artifacts and features, thereby reducing the site's integrity (Wildesen 1982; Wood and Johnson 1978). It can be difficult for installation cultural resources managers to estimate past and current training impacts to archaeological resources due to the training community's lack of record keeping regarding dates, durations, types, and intensities of training activities that would facilitate the development of training "dose"/archaeological integrity "response" relationships.

Archaeology has borrowed from chemistry a wide range of investigative techniques (Pollard et al. 2007). Early applications focused on chronology and the identification of the geographic origin of various materials. Examples of recent applications include the use of strontium ratios to infer diet, the sequencing of DNA to investigate genetic relationships, and thence, population interactions and movements, etc. Relatively little attention has focused on basic issues of site formation, detection, and characterization. One important exception to this has been the use of horizontal variation in phosphorous to determine site dimensions and intra-site variation in the intensity of occupation (Schlezinger and Howes 2000). Similarly, recent research has demonstrated that horizontal variability in the abundance of certain elements (P, Mg, Ca, K, Cu, Zn) can also be used to detect site boundaries and intra-site spatial patterning in particular past human activities (Entwistle et al. 1998, 2000a, 2000b; Konrad et al. 1983; Middleton 2004; Middleton and Price 1996).

Vertical patterning/stratification in the abundance of chemical elements within near surface soil horizon interfaces has received far less attention by archaeologists. A few archaeological studies have used variation in P to differentiate cultural from sterile layers in deeply stratified sites (often in alluvial, cave, rock shelter settings, as well as tells) (Ahler 1973; Davidson 1973; Sanchez et al. 1996). Similarly, very little research has been done concerning the implications for archaeology of inter-horizon variation in SOC and other chemical elements.

An extensive body of previous research in soil science has demonstrated that near surface soil horizons predictably differ in the vertical stratification of SOC (Boyer and Groffman 1996; Franzluebbers 2002), macroaggregates (Grandy and Robertson 2006), and chemical elements. Natural pedogenic processes, particularly plant allocation (Jobbagy and Jackson 2000, 2001) 
produce significant stratification in soil geochemical (e.g. total/organic/inorganic C, humic acid, P, and pH) (Gebhart et al. 1994; Davidson and Ackerman 1993) and physical (clay particle accumulation and orientation, particle size distribution, bulk density) (Querajeta et al. 2000) properties. Vertical patterning and inter-horizon differentiation in these properties is continuously modified but not eradicated by weathering, bioturbation, and other natural processes (Wildesen 1982; Wood and Johnson 1978), whereas military training and other human activities have the potential to completely destroy these vertical patterns. To illustrate these disturbance phenomena, refer to Figure 1 and note that all soils have naturally occurring layers that change with depth called soil horizons. These horizons are unique for each soil type and are formed by naturally occurring processes (Brady 1974). Even in arid ecosystems where soil genesis occurs over very long time frames and A horizon loss due to anthropogenic and aeolian processes is common, vertical horizon stratification is detectable and can be used to estimate impacts to embedded archaeological resources. There are five predominate soil forming factors that interact to produce every type of soil in the world. These factors are: 1) parent material, 2) climate, 3) topography, 4) plant growth (such as forest or prairie), and 5) time (Singer and Munns 1987).

A simplified list of the master soil horizons usually present includes:

“O” - Surface layers dominated by organic material.

"A" - Mineral horizons formed at the surface or below an O horizon and containing accumulated decomposed organic matter. This layer is normally rich in SOC, N, and P.

"E" - Mineral horizon whose main feature is the loss of silicate clay, Fe, or Al, leaving a concentration of resistant sand and silt particles.

"B" - Horizons formed below an A, E, or O and dominated by accumulation of silicate clay, $\mathrm{Fe}, \mathrm{Al}$, carbonates, gypsum, $\mathrm{Si}$, and macroaggregates.

"C" - Horizons excluding hard bedrock and little affected by soil genesis. 


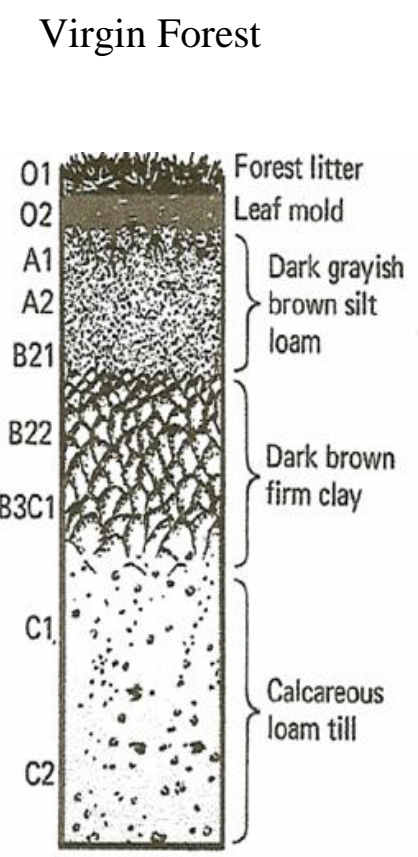

Cultivated

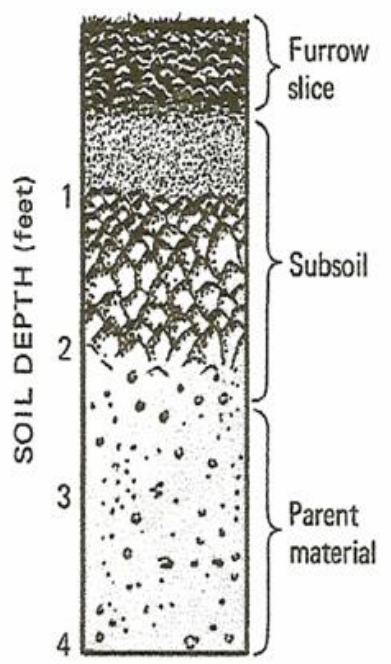

Cultivated with

Intact Archaeological

Deposits

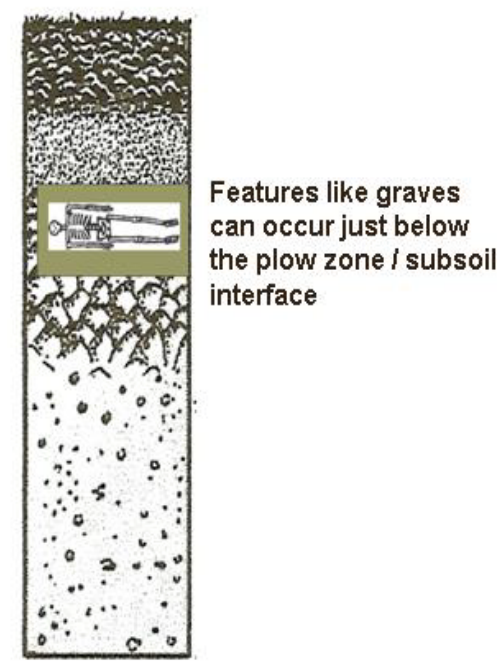

Figure 1. A conceptualized example of a soil profile illustrating changes in vertical stratification of soil horizons due to disturbance. Intact archaeological deposits often occur immediately below the $\mathrm{A} / \mathrm{B}$ horizon interface.

The virgin forest soil profile in Figure 1 illustrates the types and sequences of soil horizons that typically occur in well developed soils under forested conditions. In virgin soils, the A horizon will be distinguished by darker color due to the increased organic matter (or SOC) and insoluble elements such as P. This horizon will also typically have strong soil structure (as exemplified by increased stable soil macroaggregates) and high levels of soluble elements such as $\mathrm{N}$ and $\mathrm{K}$. The $\mathrm{B}$ horizon is the zone of accumulation where compounds/materials have moved downward into the soil profile with water infiltration and percolation. This zone will be typified by the increased levels of macroaggregates and silicate clays (which will change the soil texture and soluble compounds such as $\mathrm{Fe}, \mathrm{Ca}, \mathrm{Mg}$, and $\mathrm{Al}$ ). The $\mathrm{C}$ horizon is that part of the soil that is only slightly changed from the parent material that was present when the soil formation process started.

The cultivated soil profile (Figure 1) illustrates the change that may occur when land is plowed, cultivated, or otherwise disturbed. The furrow slice portion of the profile (Ap for A horizon plowed) is that part of the soil profile which has been plowed/disturbed and therefore has been mixed and homogenized, resulting in a destruction of the vertical patterns observed for many elements and compounds such as SOC, P, Ca, and Mg. This disturbance will also reduce or destroy the soil macroaggregate structure. Note, however, that the vertical patterns at the interface between the furrow slice (Ap) and the B horizon remain intact unless the disturbance is extreme and can be used as an indicator of potential disturbance or non-disturbance to archaeological features residing within the $\mathrm{B}$ horizon. As an example, consider that many metals $(\mathrm{Cu}, \mathrm{Zn}, \mathrm{Pb})$ are largely confined to the A or Ap horizons and any departure from this expected distribution with depth, when compared to a similar undisturbed profile of the same mapped soil series, may be 
indicative of horizon inversion from physical impacts such as training. Similar relationships would also be expected for parameters such as $\mathrm{pH}$, electrical conductivity (EC), and soil carbon.

Figure 1 also illustrates the occurrence of intact archaeological deposits immediately below the $\mathrm{A} / \mathrm{B}$ interface (see discussion below).

Prehistoric human occupation introduces additional complexity to these inter-horizon differences in soil parameters. In the past, sustained human occupation almost invariably resulted in the deposition of a variety of organic (human waste, remains of plants and animals used for food and shelter) and inorganic (lithic, ceramic) materials across occupational surfaces. In many cases, long-term and/or intense occupation resulted in an aggrading surface, ranging from the development of thin layers of human-generated "midden" sediments that are common at North American prehistoric and early historic sites to the topographically dramatic tells of the Middle East.

Modern human activities can have profound effects on soils and anthropogenic deposits (Ayers 1994; Ayers et al. 1990). Agricultural practices such as plowing and disking of the uppermost 20-30 cm can impede the development of a discrete zone of organic matter accumulation and homogenize and compact the Ap horizon (Elliott 1986). Plowing and rutting from vehicle traffic and other sources (e.g., livestock) irrevocably alter the horizontal and vertical spatial relationships among artifacts, precluding many inferences about past activities (Knoerl and Versaggi 1984, Lewarch and O’Brien 1981). However, deeper cultural strata and the lower portions of relatively isolated archaeological features (e.g. processing pits, house floors, graves) that extend below the disturbed levels often retain scientific and cultural value. Such features often represent assemblages of tools, plant and animal remains, etc. that were either functionally related (used together in the context of particular activities like food processing or storage) or at least represented a relatively brief time interval. At sites that were occupied over long time intervals, numerous features that individually represent brief time intervals may provide scientifically important opportunities to track changes in human economic and social practices.

In many regions, past occupations that occurred at or near the present ground surface have already been extensively disturbed by decades of historic plowing, livestock grazing, and urban expansion. Artifacts that were originally deposited on past living surfaces have been laterally and (to a limited extent) vertically displaced, reducing their potential contribution to inferences about the spatial and functional relationship in past activities. Archaeological studies have demonstrated, however, that historic and modern plowing does not move artifacts great distances. Thus, the spatial distributions of artifacts in the plow zone continue to have some value as indications of the spatial distribution of past activities. In the Eastern U.S., for example, localized concentrations of prehistoric pottery are often good indications of the location of architectural remains and related facilities. State, Federal, and Tribal agencies with oversight authority on compliance with historic preservation laws often view extensive impacts to previously plowed or grazed nearsurface soils as unacceptable.

Far more important to archaeological inferences than artifacts in plow zones are the "features" (constructed facilities) that often extend well below plow-disturbed near surface soils (illustrated in Figure 1). Throughout much of North America, prehistoric people stored perishable foods and other valued items in subsurface pits. These acted like small "root cellars", protecting their con- 
tents from excessive moisture, and animal and human predators. Other types of features that typically extend below plow-disturbed soil layers include prepared hearths, burials, and the floors and basins of subterranean houses. The occurrence of such features at substantial prehistoric and early historic habitation sites is a primary reason why State, Federal, and Tribal historic preservation advocates forbid or restrict ground-disturbing activities.

With the exception of depositional environments like floodplains, the uppermost portions of intact cultural features occur immediately below the base of the plow zone or Ap-horizon. Archaeological sites in wooded or otherwise protected areas that have never been plowed are typically assumed to have very high scientific and, in some cases, cultural value. In many situations, it may be acceptable to conduct military training activities that do not disturb sub-plow zone or sub-Ap horizon deposits. Training exercises that involve the use of heavy vehicles may well be acceptable under suitably dry conditions, etc. What is not acceptable are activities whose impacts extend below the base of the plow zone or Ap-horizon that has previously been disturbed by plowing, grazing or even past training. Such disturbance risks unacceptable (and unlawful) damage to intact cultural deposits. Thus, the interface between the A or Ap horizon and the immediately underlying B or E horizon is the threshold between potentially acceptable and always unacceptable impacts. In that sense, the near surface horizon interface is an integrator of activities on the surface (e.g., military training) and the condition of intact subsurface archaeological deposits. The presence of intact versus degraded inter-strata differences in the presence/absence or relative abundance of chemical elements and soil physical properties is thus directly related to, and informative about, the condition (integrity) of archaeological deposits (artifacts and features).

Some soils are characterized by the preservation of organic contents, creating a clear difference in soil color and texture between the A or Ap and B or E horizons. Under ideal circumstances, cultural resource management personnel with proper training and experience can visually detect these soil horizon interfaces. In many situations, however, environmental conditions do not favor the persistence of organic stains. This is particularly true in the sandy soils that characterize many DOD training installations (e.g., Fort Benning, GA, Fort Bragg, NC, Fort Drum, NY). This situation is exacerbated by the fact that many installation CRM personnel do not have extensive training or experience in "reading” soils. The intent of this SERDP project was to develop a method that would provide an important capability to monitor the impacts of recent training on the condition of these soil horizon interfaces. Finding that the previously distinct interface has been degraded by recent training will serve as an important indication that intact cultural deposits could be at risk. Conversely, finding that near surface horizon interfaces remain intact following recent training would indicate that such training, under similar conditions at similar sites, would not degrade the integrity of archaeological deposits.

The predictable vertical stratification patterns described above suggest that for a known soil, the level of disturbance to archaeological resources should be detectable using simple soil sampling and analysis techniques, especially if the disturbance extends into and alters the Ap/B horizon interface. Since soil survey maps are available for all military training grounds and provide detailed descriptions of the soil profiles at any given training site location, we believe that Ap/B horizon disturbance indicators can be coupled with field validated soil survey maps of military training sites and used to determine the risk of adverse impacts to intact archaeological deposits from training activities. 
Military installations across the country are characterized by a wide range of variability in factors such as soil texture, seasonal variation in soil moisture, vegetation cover, the nature of the local archaeological deposits, and the nature of military training and other military sponsored activities (e.g, agricultural out-leases or grazing). The range of variability would make it a daunting task for this project to correlate the intensity (“dose”) of military training with the degree of damage to a site's integrity throughout all possible variations. Fortunately, conditions within individual military installations are much less variable. Cultural resource personnel are often very familiar with the range of training activities at their own installations. They would be able to use the methodology proposed here in conjunction with the widely available soil survey maps that provide detailed information on soil profile characteristics to develop an understanding of the types of training actions that do not disturb soil interfaces under particular conditions, as well as those that do risk damage to intact deposits. In other words, installation personnel could accomplish the task of correlating training with impacts to near surface soil interfaces and, thence, potential adverse impacts to underlying intact archaeological deposits. 


\section{MATERIALS AND METHODS}

We selected prehistoric archaeological habitation sites at three Department of Defense (DoD) facilities that have different climates, soils, and ecosystems. These installations were Fort Benning, GA, Fort Riley, KS, and Yakima Training Center, WA, and encompass an adequate range of environmental conditions and soil types necessary to assess the suitability of selected soil compositional variables for use as indicators of horizon interface disturbance and potential damage to underlying archaeological resources. Archaeology sites were identified, surveyed, and subsequently selected following consultation with the installation Cultural Resources Manager and other relevant offices. A minimum of four habitation sites were selected at each installation to ensure a wide range of variability in topography, soil chemistry and texture, and plant community type. Descriptions of these sites are provided below. The habitation sites selected had been previously evaluated for NRHP eligibility status and adverse impacts from military training had been documented.

In the development of our hypotheses for this proposal, we recognized the following characteristics of disturbance with respect to soil chemistry: 1) Disturbance has been shown to alter vegetation which in turn will affect nutrient distribution according to above and below ground biomass production; 2) Disturbance has been shown to modify soil moisture content and soil profile water distribution, which influences nutrient distribution; 3) Soil disturbance has been shown to change soil structure, which in turn may impact nutrient distribution. However, by ensuring each archaeological habitation site and adjacent non-site area occurred on the same soil series, the influence of disturbance induced changes in soil moisture, soil texture, soil structure, and plant community were minimized and the impacts of training disturbance on elemental distribution within the soil profile was maximized. Therefore, at each archaeological habitation site, we determined soil series using established soil mapping and identification protocols and subsequent comparison to USDA-NRCS soil maps in order to accurately identify adjacent non- site areas occurring on the same soil series that would serve as non-habitation site controls.

Each archaeological site and adjacent non-site area was then surveyed to provide a floristic species and foliar cover inventory and evaluated for obvious mechanized maneuver training disturbances (vehicle ruts and tracks, disturbed/flattened vegetation communities, compacted staging areas, etc) and subdivided based on level of training disturbance. This arrangement provided essentially four treatments per site: (1) archaeological site/no-training, (2) site/training, (3) nonsite/no-training, and (4) non-site/training. The non-habitation site areas were contiguous or adjacent to archaeological sites, but were not archaeological sites per se.

For each selected archaeological site (and adjacent non-site area) at Fort Benning, GA, Fort Riley, KS, and Yakima Training Center, WA, we collected six soil core samples (8 cm diameter) for each treatment group to depths that ensured sampling below the A/B interface and into the "B" horizon. The initial soil core sample from each treatment group at each archaeological site was evaluated/mapped for visual features including color, horizonation, and obvious textural characteristics to facilitate classification using USDA-NRCS mapping guidelines (USDA-NRCS 2009). Initial cores from the four treatment groups were compared for similarity with regard to texture, color, and horizonation to verify that all treatment groups occurred on the same soil series. Following the initial core collection and evaluation for similarity and classification purpos- 
es, an additional five soil cores were mapped, GPS located, and subsequently collected from each of the four treatment groups. All cores were collected to a minimum depth of $65 \mathrm{~cm}$, however, site conditions allowed some cores to be collected to deeper depths. Each core was collected using a butyrate probe liner for stability, ease of transport, and ease of subdividing (Prior, et al. 2004). Following collection, the cores were measured, capped, and transported to laboratory facilities for sub-division and analyses.

As part of this research, a proof-of-concept companion study designed to gain insight regarding "dose" of training intensity and "response” of soil variables was established at Fort Riley, KS. During October 2010, a 100 meter long dose response transect was established at Fort Riley on Wymore silty-clay loam soils (Fine, smectitic, mesic Aquertic Argiudolls) (USDA-NRCS, 2009), a soil series common to two of the previously established archaeology experimental sites. Vegetation was characterized by native tallgrass prairie species such as Indiangrass (Sorghastrum nutans), big bluestem (Andropogon gerardii), switchgrass (Panicum virgatum), and little bluestem (Schizachyrium scoparium) with a small component of smooth brome (Bromus inermis) and goldenrod (Solidago spp). Following transect establishment, two undisturbed soil cores, representing the control, were collected to a minimum depth of $75 \mathrm{~cm}$. Immediately after these control samples were collected, M1A1 tank traffic was imposed upon the entire length of the transect, followed by collection of two additional soil core samples from the first 10-m segment (1-pass) of the transect. Immediately after the 10-m samples were collected, M1A1 traffic was again imposed upon the transect, followed by the collection of two more soil core samples from the 10 to $20 \mathrm{~m}$ transect segment (2-passes). This protocol was repeated eight more times, resulting in soil core samples being collected from segments representing 3, 4, 5, 6, 7, 8, 9, and 10 M1A1 tank passes.

At the laboratory, each core collected from experimental plots at Fort Benning, GA, Fort Riley, $\mathrm{KS}$, and the "dose/response" transect at Fort Riley, KS, was subdivided into $5 \mathrm{~cm}$ increments, dried at $55 \mathrm{C}$, and processed to pass through a $0.15 \mathrm{~mm}$ mesh screen. Soil cores retrieved from Yakima Training Center, WA, were undergoing physical preparation (segmenting, sieving, grinding) for chemical analyses upon project termination and laboratory analyses were not completed for this set of samples. Total $\mathrm{N}$ and $\mathrm{C}$ concentrations were determined using a LECO Truspec (Swift, 1996). Soil pH was measured with a Robotic pH meter (AS-3000 Dual pH Analyzer, LabFit, Burswood, Australia) using a 1:1 soil/solution ratio $\left(0.01 \mathrm{M} \mathrm{CaCl}_{2}\right)$ (Kissel et al., 2009). Soil lime buffer capacity and cation exchange capacity (CEC) were measured with $\mathrm{Ca}(\mathrm{OH})_{2}$ titration (Kissel et al., 2007). Soil samples were extracted using Mehlich extractants (Mehlich, 1953, 1984) and measured by an inductive coupled plasma spectrophotometer (Eviro I ICAP Spectrometer, Thermo Jarrell-Ash, Franklin, MA) for Al, B, Ca, Cd, Cr, Cu, Fe, K, Mg, $\mathrm{Mn}, \mathrm{Mo}, \mathrm{Na}, \mathrm{Ni}, \mathrm{P}, \mathrm{Pb}$, and $\mathrm{Zn}$. Soil samples were also processed to determine total digestible elements using $\mathrm{HNO}_{3}$ Microwave Digestion procedures (EPA Method 3051) on a CEM Mars5 digester (CEM Corporation, Matthews, NC). Soil digest samples were analyzed for total P, K, $\mathrm{Ca}, \mathrm{Mg}, \mathrm{S}, \mathrm{Mn}, \mathrm{Fe}, \mathrm{Al}, \mathrm{B}, \mathrm{Cu}, \mathrm{Zn}, \mathrm{Na}, \mathrm{Ni}, \mathrm{Pb}$, and $\mathrm{Cr}$ using an inductive coupled plasma spectrophotometer (EPA Method 200.7).

Because the focus of this research was to identify soil indicator variables that could be used across wide geographic and edaphic gradients to detect site disturbance activities sufficient to impact archaeological resources, data from each archaeological habitation and non-habitation 
site within each installation were combined for statistical analyses. For within installation comparisons, a mixed model was utilized with sites as random effects, treatment and depth as fixed effects, and soil cores as subsamples. The treatment by depth interaction was analyzed, and means of significant effects were compared using Tukey's LSD at an alpha of 0.05. Means for significant interactions were compared using a Bonferroni adjusted Tukey's LSD (controls experiment-wise error rate) at an alpha of 0.05 . For between installation comparisons, analyses of variance were conducted with a mixed model using installation, treatment, and depth as dependent variables, site nested within installation treated as a random variable, and soil cores as subsamples. Treatment by depth interactions were used to identify divergence in distribution of soil variables with depth that could be attributed to physical disturbance (mixing, inversion, burial). Means for main effects were compared using Tukey's LSD at an alpha of 0.05. Means for significant interactions were compared using a Bonferroni adjusted Tukey's LSD (controls experimentwise error rate) at an alpha of 0.05. Data from the "dose/response" transect at Fort Riley, KS, were averaged according to number of vehicle passes and graphed to identify potential changes in the distribution of soil variables with depth due to imposed tank traffic.

\subsection{Archaeology Habitation Sites, Fort Benning, GA}

Site 1040: Site 1040 (Latitude $32^{\circ} 16^{\prime} 08^{\prime \prime} \mathrm{N}$, Longitude $84^{\circ} 50^{\prime} 34^{\prime \prime} \mathrm{W}$ ) is a multi-component site containing Terminal Archaic, Middle Woodland, historic Creek, and mid-nineteenth to early twentieth century materials. With the exception of some minor road construction, understory burning, and selective harvesting of mature oak (Quercus spp) and pine (Pinus spp) trees, the site is undisturbed. Phase II archaeological testing revealed both non-Indian and historic Creek Indian occupation (Curath et al. 2008). Further testing revealed one well feature and heavy artifact density. The quantity and quality of glass and ceramic artifacts lend themselves to potential research concerning domestic lifeways and as such, Site 1040 is considered eligible for the National Register of Historic Places (NRHP) under Criterion D and should be protected from any future land altering activities.

Site 1040 was visually inspected to ascertain areas that would serve as the archaeology on-site disturbed and undisturbed treatments. Immediately adjacent to the Site 1040 boundaries, areas that would serve as the off-site disturbed and undisturbed treatments were also identified and marked. Disturbance within the on-site and off-site treatment group areas consisted of minor road construction, bivouac, and mechanized maneuver training characterized by rutting, scraping, and piling of surface soils to depths of $5-10 \mathrm{~cm}$. Vegetation in on- and off-site treatment groups was characterized by an open canopy of mature oak and pine trees with an understory dominated by broomsedge (Andropogon virginicus), poison ivy (Toxicodendron spp), sumac (Rhus spp), and oak and pine seedlings. A significant but discontinuous layer of pine needle/oak litter was also present at both on-and off-site treatment groups. Initial cores from the four treatment groups were similar with regard to texture, color, and horizonation and were subsequently classified as Troup loamy sands (Loamy, kaolinitic, thermic Grossarenic Kandiudults) (USDANRCS 2009). A/B soil horizon interfaces for this soil series occur at 75-100 cm.

Site 1931: Site 1931 (Latitude $32^{\circ} 17^{\prime} 39^{\prime \prime} \mathrm{N}$, Longitude 84 49' 12" W) consists of a large Indian and non-Indian artifact scatter representing Terminal Archaic, Early Woodland, and late eighteenth through early twentieth century occupation (Curath et al. 2008). There is also a minor 
prehistoric component associated with the site. Although the site has been impacted by a variety of land altering activities (grading, erosion, logging, mechanized and bivouac military training), Phase II excavations proved that intact deposits still exist based on the presence of scatter, remains, and an intact cultural feature. Site 1931 is considered eligible for the National Register of Historic Places (NRHP) under Criterion D and should be protected from any future land altering activities.

Site 1931 was visually inspected to ascertain areas that would serve as the archaeology on-site disturbed and undisturbed treatments. Immediately adjacent to the Site 1931 boundaries, areas that would serve as the off-site disturbed and undisturbed treatments were also identified and marked. Disturbance within the on-site and off-site treatment group areas consisted of minor road construction, selective timber harvesting, bivouac, and mechanized maneuver training characterized by rutting, scraping, piling, and inversion of surface soils to depths of 5-10 cm. Vegetation in on- and off-site treatment groups was characterized by an open canopy of immature pine trees with an understory dominated by broomsedge, McCartney rose (Rosa bracteata), partridge pea (Chamaecrista spp), paspalum (Paspalum spp), Japanese brome (Bromus arvensis), panicgrass (Panicum spp), ragweed (Ambrosia artemisifolia), lespedeza (Lespedeza spp), and oak and pine seedlings. Except for the top 2-5 cm, initial cores from the four treatment groups were similar with regard to texture, color, and horizonation and were subsequently classified as Nankin sandy clay loams (Fine, kaolinitic, thermic Typic Kanhapludults) (USDA-NRCS 2009). A/B soil horizon interfaces for this soil series occur at 40-55 cm.

Site 2268: Site 2268 (Latitude $32^{\circ} 16^{\prime} 22^{\prime \prime} \mathrm{N}$, Longitude $84^{\circ} 49^{\prime} 09^{\prime \prime} \mathrm{W}$ ) consists primarily of a mid $19^{\text {th }}$ to early $20^{\text {th }}$ century farmstead occupation with a minor prehistoric component. Site 2268 is situated just southwest of the intersection of Goodhope and Blue Ridge roads. A structure is shown at this location on a 1908 USGS topographic map. Site impacts include understory burning, selective timber harvesting, push piles associated with road grading, excavated fighting positions, and mechanized maneuver training. Previous investigations found Site 2268 to be ineligible for the NRHP (Curath et al. 2008).

Site 2268 was visually inspected to ascertain areas that would serve as the archaeology on-site disturbed and undisturbed treatments. Immediately adjacent to the Site 2268 boundaries, areas that would serve as the off-site disturbed and undisturbed treatments were also identified and marked. Disturbance within the on-site and off-site treatment group areas consisted of selective timber harvesting and mechanized maneuver training characterized by rutting, scraping, piling, and inversion of surface soils to depths of 5-10 cm. Vegetation in on- and off-site treatment groups was characterized by an open canopy of immature pine trees with an understory dominated by broomsedge, McCartney rose, partridge pea, ragweed, lespedeza, marestail (Conyza canadensis), and oak and pine seedlings. Initial cores from the four treatment groups were somewhat similar with regard to texture, color, and horizonation, but were subsequently classified as Lucy loamy sands (Loamy, kaolinitic, thermic, Arenic Kandiudults) for the off-site disturbed and undisturbed treatment groups and as Troup loamy sands (Loamy, kaolinitic, thermic Grossarenic Kandiudults) for the on-site disturbed and undisturbed treatment groups (USDA-NRCS 2009). It was not anticipated that the subtle differences between Lucy and Troup soils would impact our ability to evaluate and identify potential soil variables for use as indicators of change due to military training. A/B soil horizon interfaces for these soil series occur at 75-100 cm. 
Site 9CE44: Site 9CE44 (Latitude 32 $25^{\prime} 02^{\prime \prime}$ N, Longitude $78^{\circ} 41^{\prime} 10^{\prime \prime} \mathrm{W}$ ) consists of a moderate Indian artifact scatter representing Early and Terminal Archaic occupations as well as Early, Middle, and Late Woodland occupations. Site impacts included selective timber harvesting, understory burning, and road construction. Previous investigations found Site 9CE44 to be ineligible for the NRHP (Curath et al. 2008).

Site 9CE44 was visually inspected to ascertain areas that would serve as the archaeology on-site disturbed and undisturbed treatments. Immediately adjacent to the Site 9CE44 boundaries, areas that would serve as the off-site disturbed and undisturbed treatments were also identified and marked. Disturbance within the on-site and off-site treatment group areas consisted of selective timber harvesting, evidence of road construction, and mechanized maneuver training characterized by rutting, scraping, piling, and inversion of surface soils to depths of $10 \mathrm{~cm}$. Vegetation in on- and off-site treatment groups was characterized by an open canopy of mature pine trees with an understory dominated by broomsedge, McCartney rose, partridge pea, ragweed, lespedeza, marestail and oak and pine seedlings. Initial cores from the four treatment groups were similar with regard to texture, color, and horizonation and were subsequently classified as Ailey loamy coarse sands (Loamy, siliceous, thermic, Arenic Fragiudults) (USDA-NRCS 2009). A/B soil horizon interfaces for this soil series occur at 80-100 cm.

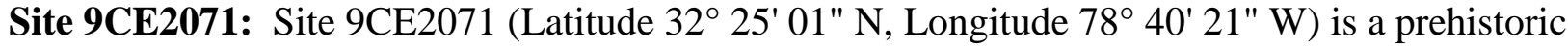
Indian site with a small non-Indian presence. The components present include Late Archaic, Terminal Archaic, undifferentiated post-Archaic, and early twentieth century. Site impacts included selective timber harvesting, understory burning, maneuver training, old bivouac pits, and old road bed remnants. Previous investigations found Site 9CE2071 to be ineligible for the NRHP (Curath et al. 2008).

Site 9CE2071 was visually inspected to ascertain areas that would serve as the archaeology onsite disturbed and undisturbed treatments. Immediately adjacent to the Site 9CE2071 boundaries, areas that would serve as the off-site disturbed and undisturbed treatments were also identified and marked. Disturbance within the on-site and off-site treatment group areas consisted of selective timber harvesting, evidence of several old road beds, mechanized maneuver training characterized by rutting, scraping, piling, and inversion of surface soils to depths of 5 to $10 \mathrm{~cm}$, and old bivouac pits. Vegetation in on- and off-site treatment groups was characterized by an open canopy of mature oak and pine trees with an understory dominated by broomsedge, panicgrass, lespedeza, sumac (Rhus spp), and oak and pine seedlings. Initial cores from the four treatment groups were similar with regard to texture, color, and horizonation and were subsequently classified as Troup loamy sands (Loamy, kaolinitic, thermic Grossarenic Kandiudults) (USDA-NRCS 2009). A/B soil horizon interfaces for this soil series occur at $75-100 \mathrm{~cm}$.

\subsection{Archaeology Habitation Sites, Fort Riley, KS}

Site 195: This historic farmstead is located on an upland ridge and is typical of $19^{\text {th }}$ century occupations in this part of the country. The site appears on a 1909 USGS map and was acquired by the Army in 1942. Information about NRHP status and the variety of buildings and other features once present at the site is not yet available, but can be provided by the Fort Riley Cultural Resource Management Office. 
Site 195 (Latitude 39 16' 09" N, Longitude 96 49' 03" W) was visually inspected to ascertain areas that would serve as the archaeology on-site disturbed and undisturbed treatments. Immediately adjacent to the Site 195 boundaries, areas that would serve as the off-site disturbed and undisturbed treatments were also identified and marked. Disturbance within the on-site and off-site treatment group areas consisted of historic agricultural practices including grazing and plowing and extensive mechanized maneuver training characterized by rutting, scraping, piling, and inversion of surface soils to depths of $4-8 \mathrm{~cm}$. Vegetation in on-site treatment groups was characterized by eastern red cedar (Juniperus virginiana) windbreaks, smooth brome (Bromus inermis), partridge pea (Chamaechrista fasciculata), ragweed (Ambrosia spp), and goldenrod (Solidago spp). Vegetation in off-site treatment groups was dominated by smooth brome, ragweed, witchgrass (Panicum capillare), sunflower (Helianthus spp), and foxtail (Setaria spp). Initial cores from the four treatment groups were similar with regard to texture, color, and horizonation and were subsequently classified as Wymore silty clay loams (Fine, smectitic, mesic Aquertic Argiudolls) (USDA-NRCS 2009). A/B soil horizon interfaces for this soil series occur at 13-20 $\mathrm{cm}$.

Site 1173: For purposes of this study, Site 1173 (Latitude 39 $14^{\prime} 29^{\prime \prime}$ N, Longitude $96^{\circ} 47^{\prime} 42^{\prime \prime}$ W) is much like Site 195. Both are historic farmsteads characterized by the remains of farm houses and associated out-buildings. Portions of Site 1173 have probably been protected from vehicle impacts by trees, whereas open areas have likely been very heavily impacted. The farmstead at Site 1173 was established around 1875, and there is good archival information available.

Site 1173 was visually inspected to ascertain areas that would serve as the archaeology on-site disturbed and undisturbed treatments. Immediately adjacent to the Site 1173 boundaries, areas that would serve as the off-site disturbed and undisturbed treatments were also identified and marked. Disturbance within the on-site and off-site treatment group areas consisted of historic agricultural practices including grazing and plowing and extensive mechanized maneuver training characterized by rutting, scraping, piling, and inversion of surface soils to depths of 3-6 cm. Vegetation in on-site treatment groups was characterized by eastern red cedar windbreaks, smooth brome, partridge pea, ragweed, and goldenrod. Vegetation in off-site treatment groups was dominated by smooth brome, ragweed, witchgrass, sunflower, and foxtail. Initial cores from the four treatment groups were similar with regard to texture, color, and horizonation and were subsequently classified as Wymore silty clay loams (Fine, smectitic, mesic Aquertic Argiudolls) (USDA-NRCS 2009). A/B soil horizon interfaces for this soil series occur at $13-20 \mathrm{~cm}$.

Site 317: Site 317 (Latitude 39 17' 29" N, Longitude 96 57' 09" W) is a prehistoric site with documented surface artifact scattering. This site is located on a relatively level terrace adjacent to Timber Creek. Portions of Site 317 were under cultivation during the SERDP fieldwork. When initially recorded in 1978, Site 317 was manifest by chert flakes, a fragment of a bifacial tool, and burned limestone. The site first came to the attention of archaeologists during an assessment of damage to archaeological sites at Fort Riley (Richardson and Hargrave 1998). No artifacts were observed on the surface during the 2009 SERDP fieldwork, suggesting that Site 317 represents the type of low density artifact scatter common at Fort Riley. 
Site 317 was visually inspected to ascertain areas that would serve as the archaeology on-site disturbed and undisturbed treatments. Immediately adjacent to the Site 317 boundaries, areas that would serve as the off-site disturbed and undisturbed treatments were also identified and marked. Disturbance within the on-site and off-site treatment group areas consists of historic agricultural practices including grazing, plowing, and limited mechanized maneuver training characterized by discontinuous rutting, scraping, and piling of surface soils. Much of the on- and off-site disturbance treatment group areas have experienced extensive historic and contemporary plowing to support production, rotation agriculture (corn/soybean/wheat/fallow) and as a result, surface soils are homogenous to depths of $15 \mathrm{~cm}$. Conversely, on- and off-site undisturbed treatment groups have not been significantly impacted by contemporary land altering activities as evidenced by dense stands of native tallgrass prairie plant species: Indiangrass (Sorghastrum nutans), big bluestem (Andropogon gerardii), switchgrass (Panicum virgatum), little bluestem (Schizachyrium scoparium), and goldenrod. Vegetation in disturbance treatment groups was characterized by common agricultural weed species such as downy brome (Bromus tectorum), foxtail, and ragweed. Initial cores from the four treatment groups were similar with regard to texture, color, and horizonation and were subsequently classified as Reading silt loams (Finesilty, mixed, superactive, mesic Pachic Argiudolls) (USDA-NRCS 2009). A/B soil horizon interfaces for this soil series occur at $30-36 \mathrm{~cm}$.

Site 318: Site 318 (Latitude 39 $17^{\prime} 21^{\prime \prime}$ N, Longitude $96^{\circ} 57^{\prime} 09^{\prime \prime} \mathrm{W}$ ) is a prehistoric site with documented surface artifact scattering. This site is located on a relatively level terrace north of Site 317 and also adjacent to Timber Creek, since these perennial streams provided necessary elements for prehistoric habitation and occupation. Portions of Site 318 were covered by a dense stand of annual weeds representing the fallow cycle of the current agricultural production system. No artifacts were observed on the surface during the 2009 SERDP fieldwork, suggesting that Site 318 represents the type of low density artifact scatter common at Fort Riley.

Site 318 was visually inspected to ascertain areas that would serve as the archaeology on-site disturbed and undisturbed treatments. Immediately adjacent to the Site 318 boundaries, areas that would serve as the off-site disturbed and undisturbed treatments were also identified and marked. Disturbance within the on-site and off-site treatment group areas consists of historic agricultural practices including grazing, plowing, and limited mechanized maneuver training characterized by discontinuous rutting, scraping, and piling of surface soils. Much of the on- and off-site disturbance treatment group areas have experienced extensive historic and contemporary plowing to support production, rotation agriculture (corn/soybean/wheat/fallow) and as a result, surface soils are homogenous to depths of $15 \mathrm{~cm}$. Conversely, on- and off-site undisturbed treatment groups have not been significantly impacted by contemporary land altering activities as evidenced by dense stands of native tallgrass prairie plant species: Indiangrass (Sorghastrum nutans), big bluestem (Andropogon gerardii), switchgrass (Panicum virgatum), little bluestem

(Schizachyrium scoparium), and goldenrod. Vegetation in disturbance treatment groups was characterized by common agricultural weed species such as downy brome (Bromus tectorum), foxtail, and ragweed. Initial cores from the four treatment groups were similar with regard to texture, color, and horizonation and were subsequently classified as Reading silt loams (Finesilty, mixed, superactive, mesic Pachic Argiudolls) (USDA-NRCS 2009). A/B soil horizon interfaces for this soil series occur at $30-36 \mathrm{~cm}$. 


\subsection{Archaeology Habitation Sites, Yakima Training Center, WA}

Site 45YK174: Site 45YK174 (Latitude 46 36' 29" N, Longitude 119 58' 50" W) is manifest as a light surface scatter of prehistoric chert flakes, some of which appear to have been modified by or for use as cutting or scraping tools. No temporally diagnostic artifacts have been recovered, however, archaeological site forms indicate that intact deposits could be present at deeper levels. The site is located within $30 \mathrm{~m}$ of Cold Creek Road, on a level alluvial terrace.

Site 45YK174 was visually inspected to ascertain areas that would serve as the archaeology onsite disturbed and undisturbed treatments. Immediately adjacent to the Site 45YK174 boundaries, areas that would serve as the off-site disturbed and undisturbed treatments were also identified and marked. Disturbance within the on-site and off-site treatment group areas consisted of mechanized maneuver training characterized by rutting, scraping, and piling of surface soils to depths of $5-10 \mathrm{~cm}$. The archaeological site form indicates that approximately $75 \%$ of the site area has been disturbed by historic overgrazing and erosion. Vegetation in on- and off-site treatment groups was characterized by typical shrub-steppe vegetation (Meinke et al, 2009), although the disturbed treatment groups had significantly more cheatgrass (Bromus tectorum) than the undisturbed treatment groups. Vegetation was characterized by sagebrush (Artemisia spp), rabbitbrush (Chrysothamnus spp), buckwheat (Eriogunum spp), bluebunch wheatgrass, (Pseudoroegneria spicata), Basin wildrye (Leymus cinerus), western wheatgrass (Pascopyrum smithii), Sandburg bluegrass (Poa secunda), Indian ricegrass (Achnatherum hymenoides), squirreltail (Elymus elymoides), and needle-and-thread (Hesperostipa comata). Initial cores from the four treatment groups were similar with regard to texture, color, and horizonation and were subsequently classified as Esquatzel silt loams (Coarse-silty, mixed, superactive, mesic Torrifluventic Haploxerolls) (USDA-NRCS 2009). A/B soil horizon interfaces for this soil series occur at $17-50 \mathrm{~cm}$.

Site 45YK184: Site 45YK184 (Latitude 46 35' 58" N, Longitude $119^{\circ}$ 55' 49" W) is located on the south side of Cold Creek Road and occurs on a level alluvial terrace just north of Cold Creek proper, a deeply entrenched, perennial creek. The site was identified based on a light surface scatter of cryptocrystalline chert flakes and small chunks, and petrified wood. Artifacts reported in the archaeological site form include a tip and a base fragment of two projectile points. The latter represents a Columbia Stemmed, barbed basal notched point, a type that dates from ca. 1,500 BP to the historic era. Also recovered were a third biface fragment; ca. 46 chert, chalcedony, and petrified wood flakes; and more than 20 fragments of fire-cracked rock. The recovery of 19 of the flakes in a single shovel test (all from the uppermost $40 \mathrm{~cm}$ ), along with the presence of fire-cracked rock, suggests that artifact concentrations and possibly hearths or other features are still or were once present.

Site 45YK184 was visually inspected to ascertain areas that would serve as the archaeology onsite disturbed and undisturbed treatments. Immediately adjacent to the Site 45YK184 boundaries, areas that would serve as the off-site disturbed and undisturbed treatments were also identified and marked. Disturbance within the on-site and off-site treatment group areas consisted of mechanized maneuver training characterized by rutting, scraping, and piling of surface soils to depths of 5-10 cm. Vegetation in on- and off-site treatment groups was characterized by typical shrub-steppe vegetation (Meinke et al, 2009), although the disturbed treatment groups had signif- 
icantly more cheatgrass and mustard (Lepidium spp) than the undisturbed treatment groups. Vegetation was characterized by scattered, older sagebrush plants (Artemisia spp), rabbitbrush, buckwheat, and an understory of bluebunch wheatgrass, Basin wildrye, western wheatgrass, crested wheatgrass (Agropyron cristatum) Sandburg bluegrass, Indian ricegrass, squirreltail, and needle-and-thread. Initial cores from the four treatment groups were similar with regard to texture, color, and horizonation and were subsequently classified as Benwy silt loams (Fine-loamy, mixed, superactive, mesic Calciargidic Argixerolls) (USDA-NRCS 2009). A/B soil horizon interfaces for this soil series occur at 25-45 cm.

Site 45YK663A: Site 45YK663A (Latitude 46 35' 56" N, Longitude $119^{\circ}$ 55' 37" W) is located on a level terrace of a sloping hillside north of Cold Creek Road. The site was identified based on the recovery of numerous flakes (including obsidian), calcified bone, projectile point fragments, ground stone, and fire cracked rock from eroding hillslopes in 1999. This diversity of artifacts suggests that the site was occupied on numerous occasions by groups engaged in both hunting and gathering.

Site 45YK663A was visually inspected to ascertain areas that would serve as the archaeology onsite disturbed and undisturbed treatments. Immediately adjacent to the Site 45YK663A boundaries, areas that would serve as the off-site disturbed and undisturbed treatments were also identified and marked. Disturbance within the on-site and off-site treatment group areas consisted of mechanized maneuver training and fire break development characterized by rutting, scraping, and piling of surface soils to depths of $5-20 \mathrm{~cm}$. Vegetation in on- and off-site treatment groups was characterized by typical shrub-steppe vegetation (Meinke et al, 2009), although the disturbed treatment groups had significantly more cheatgrass, mustard, and Russian thistle (Salsola spp) than the undisturbed treatment groups. Vegetation was characterized by dense, shorter statured sagebrush plants, buckwheat, and an understory of bluebunch wheatgrass, western wheatgrass, crested wheatgrass, Indian ricegrass, and needle-and-thread. Initial cores from the four treatment groups were similar with regard to texture, color, and horizonation and were subsequently classified as Benwy silt loams (Fine-loamy, mixed, superactive, mesic Calciargidic Argixerolls) (USDA-NRCS 2009). A/B soil horizon interfaces for this soil series occur at 25-45 cm.

Site 45YK663B: Site 45YK663B (Latitude 46 35' 54" N, Longitude 119 55' 36" W) is located on a relatively level terrace, immediately north of Cold Creek proper, near Cold Creek Road. The site was identified based on the recovery of numerous flakes (including obsidian), calcined bone fragments, non-diagnostic projectile point fragments, ground stone, one hammer stone, and numerous fire cracked rock specimens. The diversity of artifacts suggests that the site was occupied on numerous occasions by groups engaged in both hunting and gathering. Most of the artifacts were from eroding cutbanks or near rodent dens or other disturbed locations. Three artifact concentrations were noted. Artifacts were recovered from shovel tests at least $80 \mathrm{~cm}$ below the surface, indicating the presence of intact deposits.

Site 45YK663B was visually inspected to ascertain areas that would serve as the archaeology onsite disturbed and undisturbed treatments. Immediately adjacent to the Site 45YK663B boundaries, areas that would serve as the off-site disturbed and undisturbed treatments were also identified and marked. Disturbance within the on-site and off-site treatment group areas consisted of mechanized maneuver training characterized by rutting, scraping, and piling of surface soils to 
depths of 5-10 cm. Due to the site's proximity to Cold Creek, historic overgrazing and associated erosion is also highly likely. Vegetation in on- and off-site treatment groups was characterized by typical shrub-steppe vegetation (Meinke et al, 2009), although the disturbed treatment groups had significantly more cheatgrass and Russian thistle than the undisturbed treatment groups. Vegetation was characterized by sparse, large/old sagebrush plants, dense, large rabbitbrush plants, Basin wildrye, buckwheat, and an understory of Sandburg bluegrass and fine fescue (Festuca spp). Initial cores from the four treatment groups were similar with regard to texture, color, and horizonation and were subsequently classified as Esquatzel silt loams (Coarsesilty, mixed, superactive, mesic Torrifluventic Haploxerolls) (USDA-NRCS, 2009). A/B soil horizon interfaces for this soil series occur at $17-50 \mathrm{~cm}$. 


\section{RESULTS AND DISCUSSION}

\subsection{Vertical Trends and Indicators}

Following laboratory analyses of soil core samples, data for each soil variable was summarized by treatment for individual sites within installations to identify potential indicators of disturbance based on trends in vertical distribution. Data for each soil variable were then summarized by treatment across installations to identify variables with wider geographic applicability for use as indicators of disturbance. This summarization and evaluation process identified seven variables that exhibited statistically significant treatment by depth interactions indicating that their pattern of distribution by depth differed according to treatment and may have potential for use as indicators of damage to archaeological deposits. Tables $1 \mathrm{a}$ and $1 \mathrm{~b}$ provide the means and standard errors for each soil variable exhibiting a significant treatment by depth interaction. The process also identified many variables that exhibited substantial inconsistency with respect to disturbance, site, and installation, thereby making them questionable candidates for use as indicators of potential damage to archaeological deposits. These variables are discussed in the following sections.

\subsection{Soil Organic Carbon}

Soil organic carbon is an excellent indicator of soil disturbance. Concentrations of carbon in soils have been extensively studied due to the interaction of soil carbon levels, atmospheric carbon dioxide concentrations, changing land uses, and implications to global warming. Organic carbon content in the soil is largely a function of ecosystem dynamics and the kinds of plant communities these ecosystems support. Plants contribute organic matter both above and below ground that is slowly converted into soil humus through the action of microbial activity, resulting in a vertical distribution of soil carbon that is characterized by high concentrations in surface and near-surface horizons that gradually decline with depth. This predictable vertical distribution pattern occurs regardless of soil parent material or climate condition, so it is applicable across wide geographic gradients. Disturbance has been shown to decrease soil organic matter (Gebhart et al., 1994) and increase the flux of carbon dioxide from soils (Reicosky and Lindstrom, 1993) through enhanced biological oxidation of soil carbon (Reicosky et al., 1995). The losses of soil carbon can be significant and can occur very quickly, with the largest portion of carbon dioxide release occurring in the first $24 \mathrm{~h}$ after disturbance (Reicosky et al., 1997). This is in strict contrast to the slow increase in soil carbon that has been measured when soil disturbance is removed (Gebhart et al., 1994; Potter et al., 1998; Potter et al., 1999)

Because soil carbon content has a predictable distribution with depth, it can be a clear indicator of disturbance due to soil mixing, inversion or redistribution. The level of redistribution is a measureable quantity directly related to the intensity and depth of the disturbance (Reicosky et al., 1997) and has been used as a long term measure of the intensity of soil disturbance in varying soil types (Torbert et al., 2004). Table 2 illustrates differences in the vertical distribution of soil carbon as a function of land use/disturbance. At Fort Riley, KS, and Fort Benning, GA, percent carbon values are higher for undisturbed treatment groups to depths of 20-30 cm when compared to disturbed treatment groups, suggesting that percent soil carbon may be useful for documenting disturbance and estimating depth of disturbance. At Fort Riley, KS, where A/B horizon interfaces of common soil series occur between $13-30 \mathrm{~cm}$, this disturbance depth may be significant for 
cultural resources below the Ap horizon. At Fort Benning, GA, however, these disturbance depths are well above the A/B horizon interfaces for common soil series $(40-75 \mathrm{~cm})$, and cultural resources contained within the B horizon would not likely be impacted.

Figure 2 illustrates the treatment by depth interaction for soil carbon, suggesting effects of disturbance to depths of at least $30 \mathrm{~cm}$ when averaged across sites and installations. Although soil carbon content is a predictable indicator of disturbance, its use as an indicator of both severity and depth of disturbance may be enhanced when used in combination or ratio with other metallic soil elements such as nickel, zinc, or chromium. 
Table 1a. Means and (standard errors) of treatment $\mathrm{x}$ depth interaction effects for soil variables with a significant interaction term using ANOVA with an alpha = 0.05. ${ }^{*} \mathrm{AD}=$ Archaeology habitation site/Disturbed; $\mathrm{AU}=$ Archaeology habitation site/Undisturbed; Ext $=$ extractable; Tot $=$ Total

\begin{tabular}{|c|c|c|c|c|c|c|c|c|}
\hline \multirow[b]{4}{*}{ Variable } & \multicolumn{8}{|c|}{ Treatment } \\
\hline & \multicolumn{4}{|c|}{$\mathrm{AD}^{*}$} & \multicolumn{4}{|c|}{ AU* } \\
\hline & \multicolumn{8}{|c|}{ Depth } \\
\hline & $\underline{0-10}$ & $\underline{10-20}$ & $\underline{20-30}$ & $\underline{30-50}$ & $\underline{0-10}$ & $\underline{10-20}$ & $\underline{20-30}$ & $\underline{30-50}$ \\
\hline C & $1.7718(0.1404)$ & $1.0255(0.1427)$ & $0.8460(0.1404)$ & .06185 (0.1418) & 2.3105 (0.1404) & $1.3402(0.1404)$ & $0.8259(0.1404)$ & $0.7798(0.1404)$ \\
\hline $\mathrm{pH}$ & $5.52(0.11)$ & $5.38(0.11)$ & $5.30(0.11)$ & $5.29(0.11)$ & $5.60(0.11)$ & $5.45(0.11)$ & $5.27(0.11)$ & $5.19(0.11)$ \\
\hline $\mathrm{Ext}^{*} \mathrm{Ca}$ & $1705.4(85.8)$ & 1240.3 (85.8) & 1197.7 (85.8) & 1143.7 (85.8) & 2151.1 (85.8) & $1498.3(85.8)$ & 1167.1 (85.8) & $1098.4(85.8)$ \\
\hline Ext Mg & 197 (20) & $189(20)$ & $222(20)$ & $235(20)$ & 237 (20) & $223(20)$ & $220(20)$ & $231(20)$ \\
\hline Ext Mn & $21.2(2.0)$ & $13.5(2.0)$ & $9.8(2.0)$ & $7.8(2.0)$ & $20.8(2.0)$ & $13.7(2.0)$ & $9.7(2.0)$ & $7.3(2.0)$ \\
\hline Ext Ni & $0.62(0.04)$ & $0.70(0.04)$ & $0.64(0.04)$ & $0.55(0.04)$ & $0.43(0.04)$ & $0.59(0.04)$ & $0.63(0.04)$ & $0.59(0.04)$ \\
\hline Tot* $\mathrm{P}$ & 204.68 (9.57) & $155.73(9.57)$ & $125.16(9.57)$ & $107.17(9.57)$ & $215.49(9.57)$ & $168.45(9.57)$ & $137.70(9.57)$ & $108.76(9.57)$ \\
\hline
\end{tabular}

Table 1b. Means and (standard errors) of treatment $\mathrm{x}$ depth interaction effects for soil variables with a significant interaction term using ANOVA with an alpha = $0.05 . *$ ND $=$ Non-archaeology/Disturbed; NU = Non-archaeology/Undisturbed; Ext = extractable; Tot = Total

\begin{tabular}{|c|c|c|c|c|c|c|c|c|}
\hline \multirow[b]{4}{*}{ Variable } & \multicolumn{8}{|c|}{ Treatment } \\
\hline & \multirow{2}{*}{\multicolumn{3}{|c|}{$\mathrm{ND}^{*}$}} & \multirow{2}{*}{\multicolumn{2}{|c|}{ Depth }} & & & \\
\hline & & & & & & & & \\
\hline & $\underline{0-10}$ & $\underline{10-20}$ & $\underline{20-30}$ & $\underline{30-50}$ & $\underline{0-10}$ & $\underline{10-20}$ & $\underline{20-30}$ & $\underline{30-50}$ \\
\hline $\mathrm{C}$ & $1.4023(0.1404)$ & $0.9078(0.1404)$ & $0.5623(0.1469)$ & $0.8469(0.1404)$ & $1.9288(0.1404)$ & $1.1383(0.1433)$ & $0.7741(0.1433)$ & $0.7163(0.1404)$ \\
\hline $\mathrm{pH}$ & $5.75(0.11)$ & $5.63(0.11)$ & $5.52(0.11)$ & $5.67(0.11)$ & $5.90(0.11)$ & $5.72(0.11)$ & $5.50(0.11)$ & $5.33(0.11)$ \\
\hline $\mathrm{Ext}^{*} \mathrm{Ca}$ & 1868.8 (85.8) & 1444.9 (85.8) & 1291.1 (85.8) & 1782.3 (85.8) & 2356.9 (85.8) & 1496.1 (85.8) & 1191.7 (85.8) & 1118.6 (85.8) \\
\hline Ext Mg & $313(20)$ & $260(20)$ & $233(20)$ & $250(20)$ & $338(20)$ & 259 (20) & $240(20)$ & $246(20)$ \\
\hline Ext Mn & $16.4(2.0)$ & $12.2(2.0)$ & $9.5(2.0)$ & $7.7(2.0)$ & $30.6(2.0)$ & $16.3(2.0)$ & $9.7(2.0)$ & $7.0(2.0)$ \\
\hline Ext Ni & $0.46(0.04)$ & $0.42(0.04)$ & $0.42(0.04)$ & $0.28(0.04)$ & $0.37(0.04)$ & $0.53(0.04)$ & $0.54(0.04)$ & $0.43(0.04)$ \\
\hline Tot* $\mathrm{P}$ & $166.25(9.57)$ & $117.46(9.57)$ & $109.96(9.57)$ & $133.84(9.57)$ & 207.03 (9.57) & $145.64(9.57)$ & 123.47 (9.57) & 110.55 (9.57) \\
\hline
\end{tabular}


Table 2. Percent carbon with depth from disturbed (D) and undisturbed (U) archaeological (A) and adjacent non-archaeological (N) site locations at Fort Riley, KS and Fort Benning, GA.

\begin{tabular}{|c|c|c|c|c|}
\hline Installation & Treatment & Depth (cm) & Mean (\%) & $\begin{array}{l}\text { Standard } \\
\text { Error }\end{array}$ \\
\hline \multirow{16}{*}{ Fort Riley } & $\mathrm{A} / \mathrm{U}$ & $0-10$ & 3.820 & 0.195 \\
\hline & & $10-20$ & 2.180 & 0.195 \\
\hline & & $20-30$ & 1.479 & 0.195 \\
\hline & & $30-50$ & 1.184 & 0.195 \\
\hline & $\mathrm{A} / \mathrm{D}$ & $0-10$ & 2.900 & 0.195 \\
\hline & & $10-20$ & 1.776 & 0.200 \\
\hline & & $20-30$ & 1.496 & 0.195 \\
\hline & & $30-50$ & 1.071 & 0.200 \\
\hline & $\mathrm{N} / \mathrm{U}$ & $0-10$ & 2.748 & 0.195 \\
\hline & & $10-20$ & 1.846 & 0.206 \\
\hline & & $20-30$ & 1.357 & 0.206 \\
\hline & & $30-50$ & 1.181 & 0.195 \\
\hline & N/D & $0-10$ & 2.138 & 0.195 \\
\hline & & $10-20$ & 1.484 & 0.195 \\
\hline & & $20-30$ & 0.915 & 0.218 \\
\hline & & $30-50$ & 1.099 & 0.195 \\
\hline \multirow{16}{*}{ Fort Benning } & $\mathrm{A} / \mathrm{U}$ & $0-10$ & 0.801 & 0.146 \\
\hline & & $10-20$ & 0.501 & 0.146 \\
\hline & & $20-30$ & 0.173 & 0.146 \\
\hline & & $30-50$ & 0.376 & 0.146 \\
\hline & $\mathrm{A} / \mathrm{D}$ & $0-10$ & 0.643 & 0.146 \\
\hline & & $10-20$ & 0.270 & 0.149 \\
\hline & & $20-30$ & 0.196 & 0.146 \\
\hline & & $30-50$ & 0.157 & 0.146 \\
\hline & $\mathrm{N} / \mathrm{U}$ & $0-10$ & 1.110 & 0.146 \\
\hline & & $10-20$ & 0.462 & 0.146 \\
\hline & & $20-30$ & 0.222 & 0.146 \\
\hline & & $30-50$ & 0.252 & 0.146 \\
\hline & N/D & $0-10$ & 0.666 & 0.146 \\
\hline & & $10-20$ & 0.331 & 0.146 \\
\hline & & $20-30$ & 0.279 & 0.146 \\
\hline & & $30-50$ & 0.595 & 0.146 \\
\hline
\end{tabular}




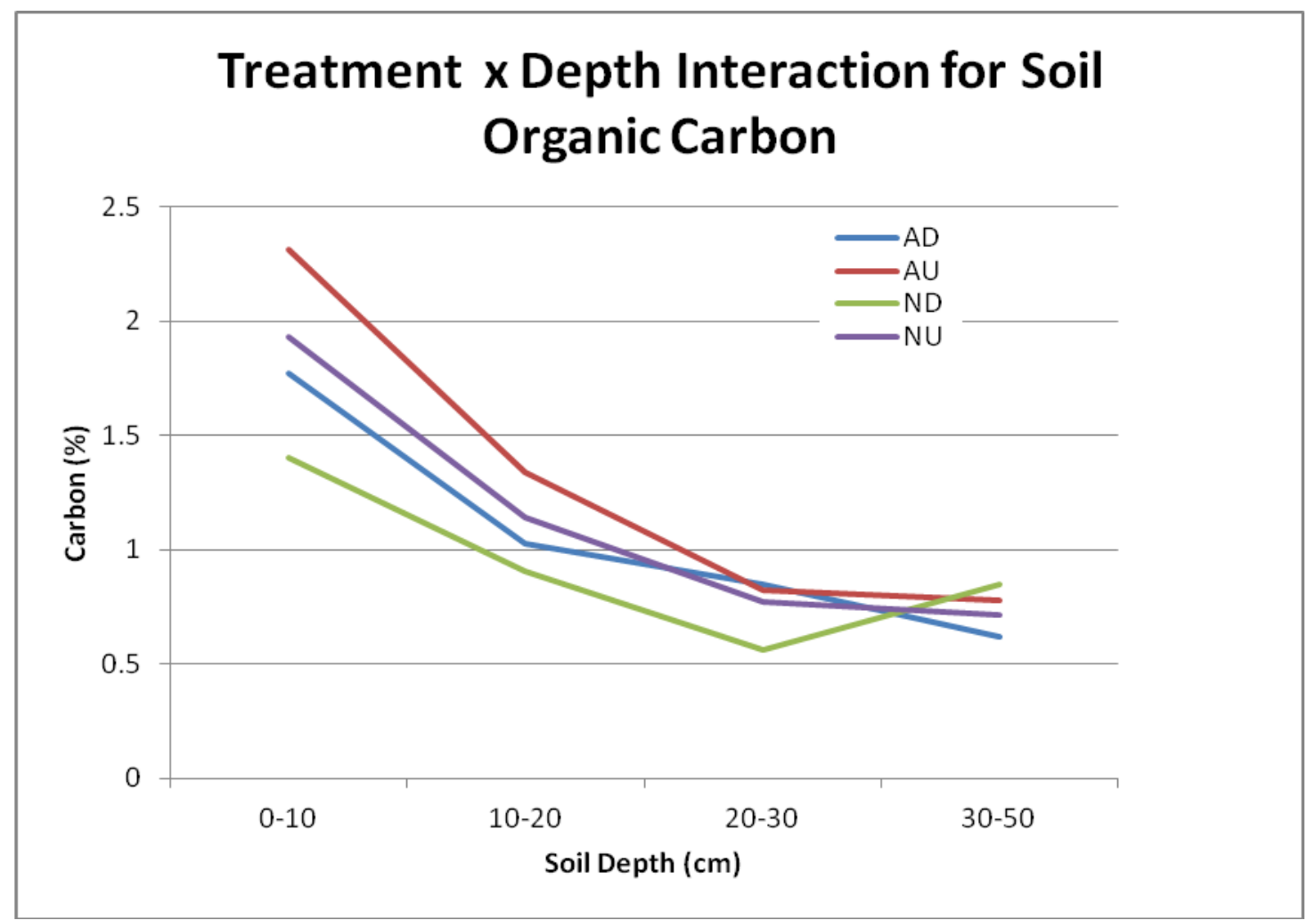

Figure 2. Percent carbon with depth from disturbed (D) and undisturbed (U) archaeological (A) and non-archaeological (N) treatment groups across all installations.

\subsection{Extractable Nickel}

Nickel content in soils is closely related to the geologic parent material. Nickel has a strong affinity for sulfur and it frequently occurs as various forms of sulfides and arsenides (Uren, 1992). Organic matter strongly adsorbs nickel, resulting in a vertical distribution that exhibits high concentrations in surface and near-surface soil horizons with a gradual decline in concentration as one moves deeper into the soil profile. These characteristics in combination with relative immobility, except in extremely acidic soils, make nickel a potential indicator that could be used to document disturbance due to soil inversion, mixing, and/or displacement. Table 3 illustrates differences in the vertical distribution of extractable nickel as a function of land use/disturbance. At Fort Riley, KS, extractable nickel concentrations were higher for disturbed treatment groups to depths of 10-30 cm when compared to undisturbed treatment groups, suggesting that extractable nickel concentrations may be useful for documenting disturbance and estimating depth of disturbance in soils with high natural levels of nickel. Mean extractable nickel concentrations at Fort Benning, GA, were lower than those at Fort Riley, KS, by nearly a factor of 10 indicating that nickel may be less useful as an indicator of disturbance in sandy soils with naturally low levels of this element. 
Table 3. Extractable nickel concentration (mg/kg) with depth from disturbed (D) and undisturbed (U) archaeological (A) and adjacent non-archaeological (N) site locations at Fort Riley, KS and Fort Benning, GA.

\begin{tabular}{|c|c|c|c|c|}
\hline Installation & Treatment & Depth (cm) & Mean (mg/kg) & $\begin{array}{l}\text { Standard } \\
\text { Error }\end{array}$ \\
\hline \multirow{16}{*}{ Fort Riley } & $\mathrm{A} / \mathrm{U}$ & $0-10$ & 0.822 & 0.079 \\
\hline & & $10-20$ & 1.108 & 0.077 \\
\hline & & $20-30$ & 1.202 & 0.077 \\
\hline & & $30-50$ & 1.121 & 0.077 \\
\hline & $\mathrm{A} / \mathrm{D}$ & $0-10$ & 1.169 & 0.078 \\
\hline & & $10-20$ & 1.324 & 0.077 \\
\hline & & $20-30$ & 1.212 & 0.077 \\
\hline & & $30-50$ & 1.044 & 0.078 \\
\hline & $\mathrm{N} / \mathrm{U}$ & $0-10$ & 0.661 & 0.078 \\
\hline & & $10-20$ & 0.985 & 0.077 \\
\hline & & $20-30$ & 1.002 & 0.077 \\
\hline & & $30-50$ & 0.790 & 0.078 \\
\hline & N/D & $0-10$ & 0.852 & 0.079 \\
\hline & & $10-20$ & 0.764 & 0.077 \\
\hline & & $20-30$ & 0.774 & 0.077 \\
\hline & & $30-50$ & 0.497 & 0.077 \\
\hline \multirow{16}{*}{ Fort Benning } & $\mathrm{A} / \mathrm{U}$ & $0-10$ & 0.087 & 0.009 \\
\hline & & $10-20$ & 0.110 & 0.009 \\
\hline & & $20-30$ & 0.090 & 0.012 \\
\hline & & $30-50$ & 0.083 & 0.010 \\
\hline & $\mathrm{A} / \mathrm{D}$ & $0-10$ & 0.086 & 0.008 \\
\hline & & $10-20$ & 0.082 & 0.009 \\
\hline & & $20-30$ & 0.074 & 0.010 \\
\hline & & $30-50$ & 0.083 & 0.009 \\
\hline & $\mathrm{N} / \mathrm{U}$ & $0-10$ & 0.092 & 0.007 \\
\hline & & $10-20$ & 0.084 & 0.008 \\
\hline & & $20-30$ & 0.088 & 0.009 \\
\hline & & $30-50$ & 0.094 & 0.009 \\
\hline & N/D & $0-10$ & 0.092 & 0.008 \\
\hline & & $10-20$ & 0.084 & 0.008 \\
\hline & & $20-30$ & 0.081 & 0.011 \\
\hline & & $30-50$ & 0.092 & 0.009 \\
\hline
\end{tabular}

Figure 3 illustrates the treatment $x$ depth interaction for extractable nickel, suggesting effects of disturbance to depths of at least $30 \mathrm{~cm}$ when averaged across sites and installations. Undisturbed treatment groups exhibit increases in nickel concentration in the 0-30 $\mathrm{cm}$ depth increment, while disturbed treatment groups show general declines to depths of $30 \mathrm{~cm}$, suggesting that this divergent distribution pattern with depth may be a potential indicator of disturbance and depth of disturbance. At Fort Riley, KS, where A/B horizon 
interfaces of common soil series occur between $13-30 \mathrm{~cm}$, this disturbance depth may be significant for cultural resources below the Ap horizon. At Fort Benning, GA, however, these disturbance depths are well above the A/B horizon interfaces for common soil series $(40-75 \mathrm{~cm})$, and cultural resources contained within the B horizon would not likely be impacted. As with soil organic carbon, the use of extractable nickel concentration as an indicator of both severity and depth of disturbance may be enhanced when used in combination or ratio with other soil variables such as organic carbon, zinc, chromium, or lead.

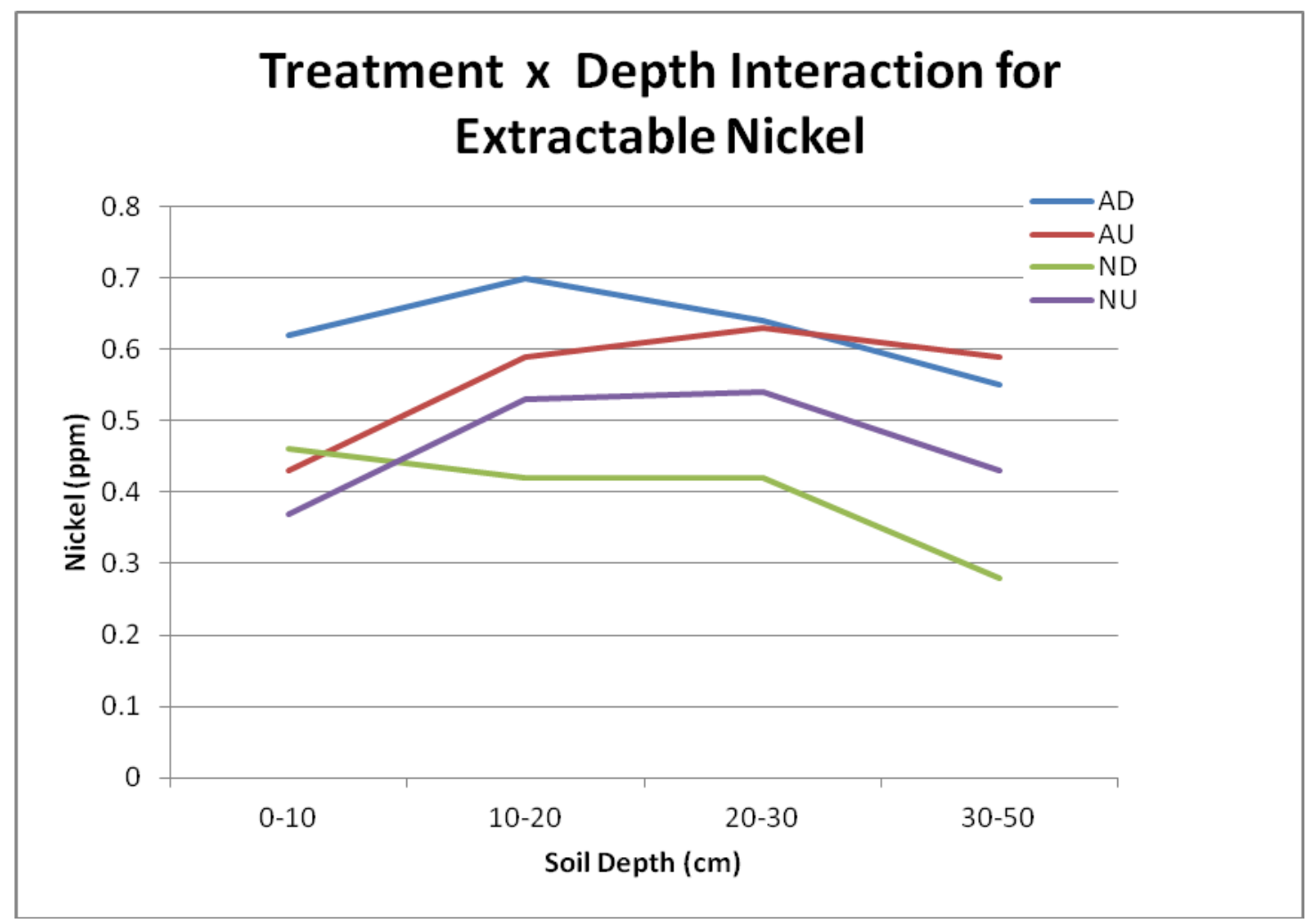

Figure 3. Extractable nickel concentration with depth from disturbed (D) and undisturbed (U) archaeological (A) and non-archaeological (N) treatment groups.

\subsection{Soil pH}

Soil pH commonly falls in a range between 4 and 9 . The more acidic soils are typically associated with regions of higher rainfall and forest vegetation types, whereas more alkaline soils are associated with regions of low rainfall and grass or shrub vegetation types. Disturbance can result in slight decreases or acidification of soils due to breakdown and mineralization of organic matter which increases solubility and transport of alkaline minerals by organic and inorganic acids. Table 4 illustrates differences in the vertical distribution of soil $\mathrm{pH}$ as a function of land use/disturbance. At both installations, soil $\mathrm{pH}$ was somewhat lower for disturbed treatment groups to depths of 10-20 cm when compared to undisturbed treatment groups, suggesting that soil $\mathrm{pH}$ may be useful for documenting disturbance and estimating depth of disturbance in soils. 
Table 4. Soil pH with depth from disturbed (D) and undisturbed (U) archaeological (A) and adjacent non-archaeological (N) site locations at Fort Riley, KS and Fort Benning, GA.

\begin{tabular}{|c|c|c|c|c|}
\hline Installation & Treatment & Depth $(\mathrm{cm})$ & Mean & $\begin{array}{l}\text { Standard } \\
\text { Error }\end{array}$ \\
\hline \multirow{16}{*}{ Fort Riley } & $\mathrm{A} / \mathrm{U}$ & $0-10$ & 6.790 & 0.155 \\
\hline & & $10-20$ & 6.347 & 0.155 \\
\hline & & $20-30$ & 5.927 & 0.155 \\
\hline & & $30-50$ & 5.681 & 0.154 \\
\hline & $\mathrm{A} / \mathrm{D}$ & $0-10$ & 6.373 & 0.155 \\
\hline & & $10-20$ & 6.107 & 0.155 \\
\hline & & $20-30$ & 5.835 & 0.155 \\
\hline & & $30-50$ & 5.679 & 0.154 \\
\hline & $\mathrm{N} / \mathrm{U}$ & $0-10$ & 7.059 & 0.155 \\
\hline & & $10-20$ & 6.633 & 0.155 \\
\hline & & $20-30$ & 6.209 & 0.054 \\
\hline & & $30-50$ & 5.945 & 0.154 \\
\hline & N/D & $0-10$ & 6.986 & 0.155 \\
\hline & & $10-20$ & 6.699 & 0.155 \\
\hline & & $20-30$ & 6.504 & 0.155 \\
\hline & & $30-50$ & 6.779 & 0.155 \\
\hline \multirow{16}{*}{ Fort Benning } & $\mathrm{A} / \mathrm{U}$ & $0-10$ & 4.404 & 0.066 \\
\hline & & $10-20$ & 4.559 & 0.066 \\
\hline & & $20-30$ & 4.620 & 0.068 \\
\hline & & $30-50$ & 4.692 & 0.066 \\
\hline & $\mathrm{A} / \mathrm{D}$ & $0-10$ & 4.676 & 0.066 \\
\hline & & $10-20$ & 4.648 & 0.066 \\
\hline & & $20-30$ & 4.768 & 0.066 \\
\hline & & $30-50$ & 4.908 & 0.068 \\
\hline & $\mathrm{N} / \mathrm{U}$ & $0-10$ & 4.747 & 0.066 \\
\hline & & $10-20$ & 4.799 & 0.066 \\
\hline & & $20-30$ & 4.791 & 0.066 \\
\hline & & $30-50$ & 4.714 & 0.066 \\
\hline & N/D & $0-10$ & 4.515 & 0.069 \\
\hline & & $10-20$ & 4.562 & 0.066 \\
\hline & & $20-30$ & 4.539 & 0.066 \\
\hline & & $30-50$ & 4.569 & 0.066 \\
\hline
\end{tabular}

Figure 4 illustrates the treatment $\mathrm{x}$ depth interaction for soil $\mathrm{pH}$ and clearly shows differences between disturbed and undisturbed treatment groups to depths of at least $20 \mathrm{~cm}$ when averaged across sites and installations. At Fort Riley, KS, where A/B horizon interfaces of common soil series occur between $13-30 \mathrm{~cm}$, this disturbance depth may be significant for cultural resources below the Ap horizon. At Fort Benning, GA, however, these disturbance depths are well above the A/B horizon interfaces for common soil series $(40-75 \mathrm{~cm})$, and cultural resources contained within the B horizon would not likely 
be impacted. Use of soil $\mathrm{pH}$ as a sole indicator of disturbance would be inadvisable due to agricultural and timber production practices, such as liming and fertilization, which can quickly change $\mathrm{pH}$ in surface soils. The predictable decreases in soil $\mathrm{pH}$ with disturbance, however, suggest that use of soil $\mathrm{pH}$ in combination or ratio with other variables such as organic carbon or metallic elements may provide evidence to ascertain severity and depth of disturbance.

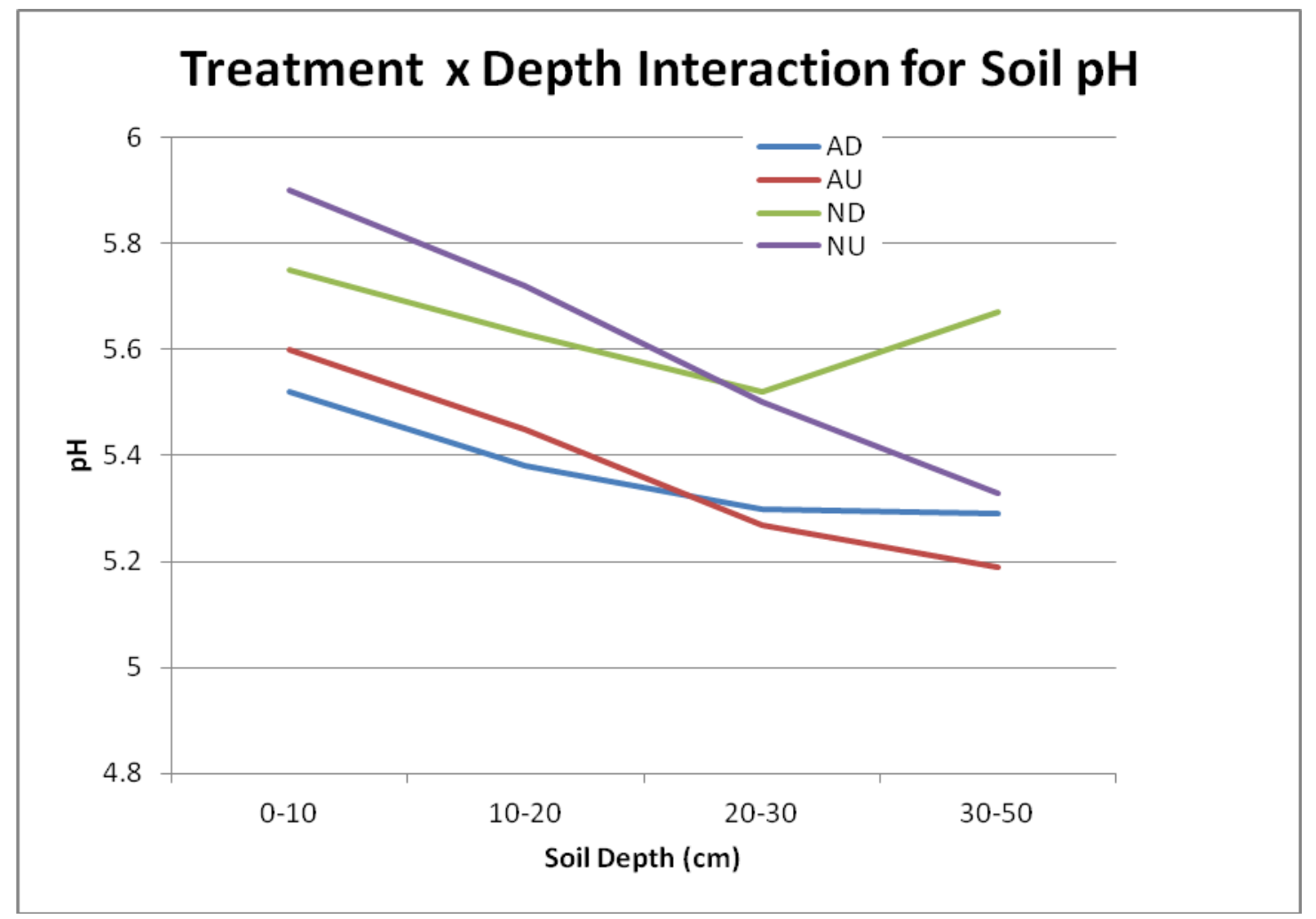

Figure 4. Soil $\mathrm{pH}$ with depth from disturbed (D) and undisturbed (U) archaeological (A) and non-archaeological (N) treatment groups.

\subsection{Extractable Calcium, Magnesium, and Manganese}

Calcium and magnesium are two important plant macronutrients and are present in soils in concentrations ranging from 0.3 to $1.0 \%$. Concentrations in arid soils are typically higher than those in humid soils because these elements can be readily solubilized and leached from the soil profile. Manganese is an important plant micronutrient present in most soils in concentrations ranging from 0.03 to $1.0 \%$. As with calcium and magnesium, concentrations in arid soils are typically higher than those in humid soils because manganese can be readily solubilized and leached from the soil profile. Tables 5, 6, and 7 illustrate differences in the vertical distribution of extractable calcium, magnesium, and manganese, respectively, as a function of land use/disturbance. At Fort Riley, KS, and Fort Benning, GA, extractable calcium, magnesium, and manganese concentrations were lower for disturbed treatment groups to depths of 10 to $20 \mathrm{~cm}$ when compared to undisturbed treatment groups. However, the treatment by depth interactions for extractable calcium, magnesium, and manganese shown in Figures 5, 6, and 7, respectively, suggest 
that these variables exhibit similar distribution by depth patterns irrespective of treatment and are probably not particularly useful as indicators of severity or depth of disturbance. This is not unexpected given that these elements are so common in most soils.

Table 5. Extractable calcium concentration (mg/kg) with depth from disturbed (D) and undisturbed (U) archaeological (A) and adjacent non-archaeological (N) site locations at Fort Riley, KS and Fort Benning, GA.

\begin{tabular}{|c|c|c|c|c|}
\hline Installation & Treatment & Depth (cm) & Mean (mg/kg) & $\begin{array}{l}\text { Standard } \\
\text { Error }\end{array}$ \\
\hline \multirow{16}{*}{ Fort Riley } & $\mathrm{A} / \mathrm{U}$ & $0-10$ & 4190.7 & 180.6 \\
\hline & & $10-20$ & 2932.6 & 180.6 \\
\hline & & $20-30$ & 2263.2 & 180.7 \\
\hline & & $30-50$ & 2118.9 & 180.6 \\
\hline & $\mathrm{A} / \mathrm{D}$ & $0-10$ & 3241.7 & 180.6 \\
\hline & & $10-20$ & 2387.6 & 180.6 \\
\hline & & $20-30$ & 2280.8 & 180.6 \\
\hline & & $30-50$ & 2153.8 & 180.7 \\
\hline & $\mathrm{N} / \mathrm{U}$ & $0-10$ & 4457.5 & 185.4 \\
\hline & & $10-20$ & 2901.8 & 180.7 \\
\hline & & $20-30$ & 2313.3 & 180.6 \\
\hline & & $30-50$ & 2174.9 & 180.6 \\
\hline & N/D & $0-10$ & 3657.3 & 184.5 \\
\hline & & $10-20$ & 2836.1 & 180.6 \\
\hline & & $20-30$ & 2516.6 & 180.7 \\
\hline & & $30-50$ & 3841.2 & 188.3 \\
\hline \multirow{16}{*}{ Fort Benning } & $\mathrm{A} / \mathrm{U}$ & $0-10$ & 111.4 & 20.7 \\
\hline & & $10-20$ & 64.1 & 20.7 \\
\hline & & $20-30$ & 70.9 & 20.7 \\
\hline & & $30-50$ & 77.8 & 20.6 \\
\hline & $\mathrm{A} / \mathrm{D}$ & $0-10$ & 189.1 & 21.6 \\
\hline & & $10-20$ & 92.9 & 20.7 \\
\hline & & $20-30$ & 114.5 & 20.6 \\
\hline & & $30-50$ & 133.6 & 20.6 \\
\hline & $\mathrm{N} / \mathrm{U}$ & $0-10$ & 256.3 & 22.9 \\
\hline & & $10-20$ & 90.4 & 20.7 \\
\hline & & $20-30$ & 70.0 & 20.8 \\
\hline & & $30-50$ & 62.3 & 20.6 \\
\hline & N/D & $0-10$ & 80.3 & 20.8 \\
\hline & & $10-20$ & 53.9 & 20.8 \\
\hline & & $20-30$ & 65.6 & 20.6 \\
\hline & & $30-50$ & 83.4 & 20.6 \\
\hline
\end{tabular}


Table 6. Extractable magnesium concentration (mg/kg) with depth from disturbed (D) and undisturbed (U) archaeological (A) and adjacent non-archaeological (N) site locations at Fort Riley, KS and Fort Benning, GA.

\begin{tabular}{|c|c|c|c|c|}
\hline Installation & Treatment & Depth (cm) & Mean (mg/kg) & $\begin{array}{l}\text { Standard } \\
\text { Error }\end{array}$ \\
\hline \multirow{16}{*}{ Fort Riley } & $\mathrm{A} / \mathrm{U}$ & $0-10$ & 454.49 & 28.19 \\
\hline & & $10-20$ & 431.32 & 28.17 \\
\hline & & $20-30$ & 424.68 & 28.19 \\
\hline & & $30-50$ & 444.32 & 28.09 \\
\hline & $\mathrm{A} / \mathrm{D}$ & $0-10$ & 371.69 & 28.47 \\
\hline & & $10-20$ & 364.26 & 28.18 \\
\hline & & $20-30$ & 429.61 & 28.18 \\
\hline & & $30-50$ & 454.23 & 28.19 \\
\hline & $\mathrm{N} / \mathrm{U}$ & $0-10$ & 641.03 & 28.47 \\
\hline & & $10-20$ & 501.04 & 28.14 \\
\hline & & $20-30$ & 463.49 & 28.19 \\
\hline & & $30-50$ & 470.41 & 28.19 \\
\hline & N/D & $0-10$ & 606.57 & 28.46 \\
\hline & & $10-20$ & 504.59 & 28.18 \\
\hline & & $20-30$ & 450.03 & 28.19 \\
\hline & & $30-50$ & 478.62 & 28.19 \\
\hline \multirow{16}{*}{ Fort Benning } & $\mathrm{A} / \mathrm{U}$ & $0-10$ & 20.10 & 2.39 \\
\hline & & $10-20$ & 13.89 & 2.33 \\
\hline & & $20-30$ & 15.15 & 2.40 \\
\hline & & $30-50$ & 17.88 & 2.39 \\
\hline & $\mathrm{A} / \mathrm{D}$ & $0-10$ & 22.75 & 2.38 \\
\hline & & $10-20$ & 13.29 & 2.36 \\
\hline & & $20-30$ & 13.56 & 2.37 \\
\hline & & $30-50$ & 15.96 & 2.39 \\
\hline & $\mathrm{N} / \mathrm{U}$ & $0-10$ & 34.11 & 2.46 \\
\hline & & $10-20$ & 17.02 & 2.37 \\
\hline & & $20-30$ & 16.49 & 2.39 \\
\hline & & $30-50$ & 20.62 & 2.40 \\
\hline & N/D & $0-10$ & 19.86 & 2.42 \\
\hline & & $10-20$ & 15.34 & 2.39 \\
\hline & & $20-30$ & 15.74 & 2.39 \\
\hline & & $30-50$ & 21.62 & 2.39 \\
\hline
\end{tabular}


Table 7. Extractable manganese concentration ( $\mathrm{mg} / \mathrm{kg}$ ) with depth from disturbed (D) and undisturbed (U) archaeological (A) and adjacent non-archaeological (N) site locations at Fort Riley, KS and Fort Benning, GA.

\begin{tabular}{|c|c|c|c|c|}
\hline Installation & Treatment & Depth (cm) & Mean (mg/kg) & $\begin{array}{l}\text { Standard } \\
\text { Error }\end{array}$ \\
\hline \multirow{16}{*}{ Fort Riley } & $\mathrm{A} / \mathrm{U}$ & $0-10$ & 26.958 & 1.406 \\
\hline & & $10-20$ & 17.451 & 1.406 \\
\hline & & $20-30$ & 12.073 & 1.410 \\
\hline & & $30-50$ & 8.661 & 1.406 \\
\hline & $\mathrm{A} / \mathrm{D}$ & $0-10$ & 27.226 & 1.406 \\
\hline & & $10-20$ & 16.161 & 1.406 \\
\hline & & $20-30$ & 9.397 & 1.406 \\
\hline & & $30-50$ & 6.853 & 1.403 \\
\hline & $\mathrm{N} / \mathrm{U}$ & $0-10$ & 23.324 & 1.409 \\
\hline & & $10-20$ & 16.917 & 1.406 \\
\hline & & $20-30$ & 10.144 & 1.400 \\
\hline & & $30-50$ & 7.336 & 1.402 \\
\hline & N/D & $0-10$ & 23.111 & 1.405 \\
\hline & & $10-20$ & 14.113 & 1.411 \\
\hline & & $20-30$ & 10.286 & 1.406 \\
\hline & & $30-50$ & 7.214 & 1.406 \\
\hline \multirow{16}{*}{ Fort Benning } & $\mathrm{A} / \mathrm{U}$ & $0-10$ & 14.619 & 2.328 \\
\hline & & $10-20$ & 9.989 & 2.328 \\
\hline & & $20-30$ & 7.345 & 2.328 \\
\hline & & $30-50$ & 5.865 & 2.327 \\
\hline & $\mathrm{A} / \mathrm{D}$ & $0-10$ & 15.169 & 2.328 \\
\hline & & $10-20$ & 10.756 & 2.330 \\
\hline & & $20-30$ & 10.116 & 2.329 \\
\hline & & $30-50$ & 8.719 & 2.328 \\
\hline & $\mathrm{N} / \mathrm{U}$ & $0-10$ & 37.778 & 2.406 \\
\hline & & $10-20$ & 15.707 & 2.329 \\
\hline & & $20-30$ & 9.276 & 2.328 \\
\hline & & $30-50$ & 6.590 & 2.331 \\
\hline & N/D & $0-10$ & 9.633 & 2.333 \\
\hline & & $10-20$ & 10.266 & 2.329 \\
\hline & & $20-30$ & 8.616 & 2.328 \\
\hline & & $30-50$ & 8.163 & 2.328 \\
\hline
\end{tabular}




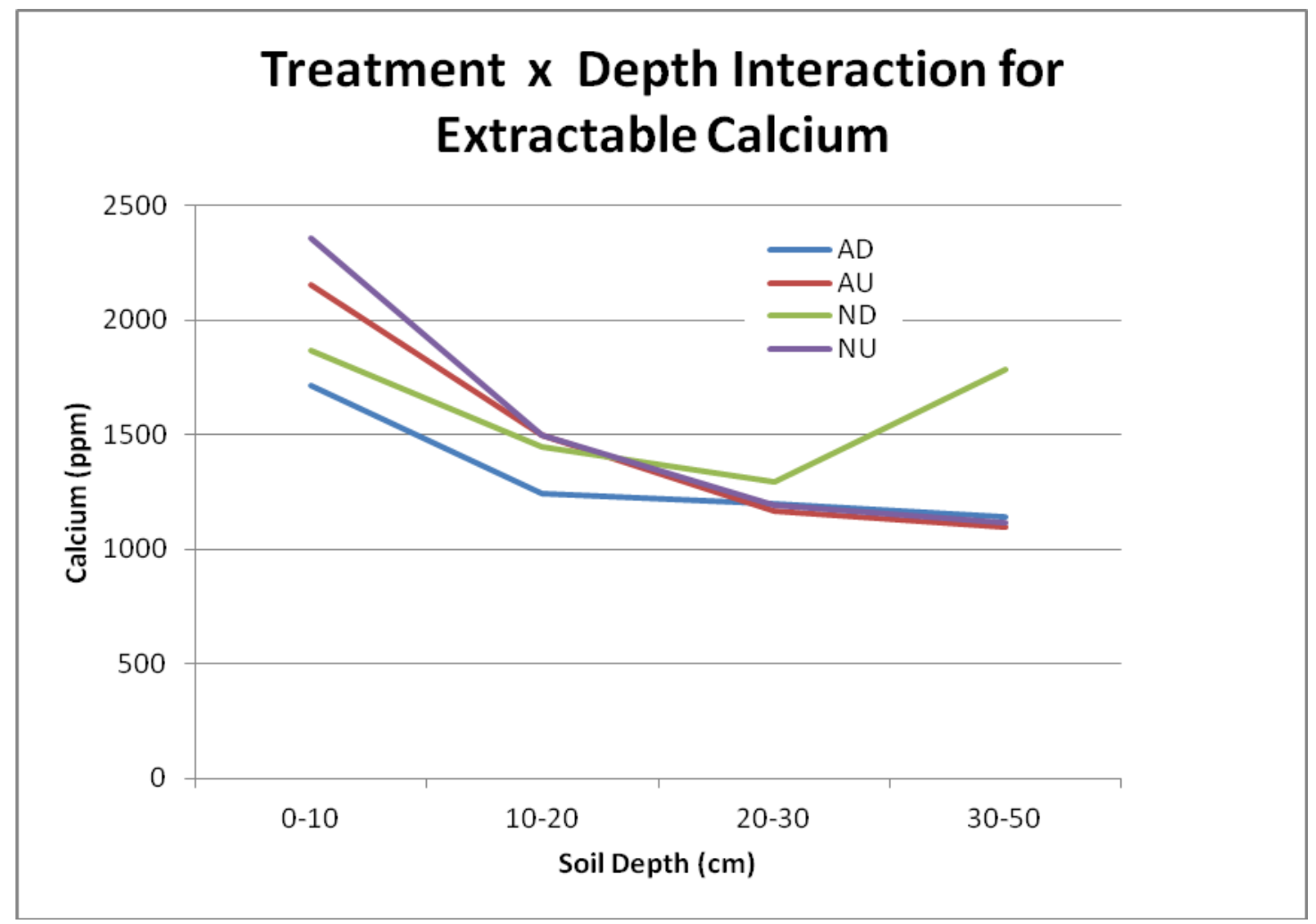

Figure 5. Extractable calcium concentration with depth from disturbed (D) and undisturbed (U) archaeological (A) and non-archaeological (N) treatment groups.

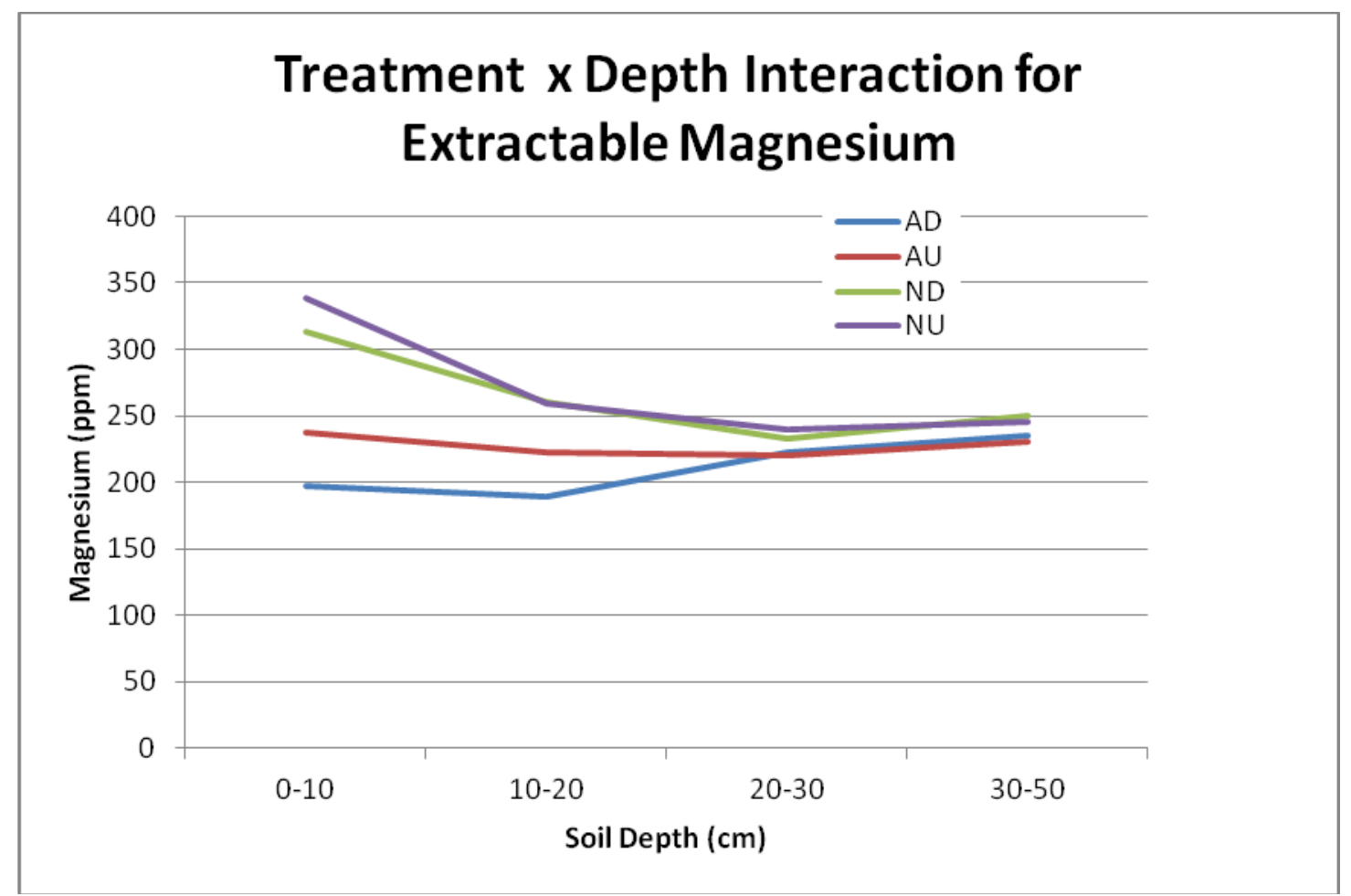

Figure 6. Extractable magnesium concentration with depth from disturbed (D) and undisturbed (U) archaeological (A) and non-archaeological (N) treatment groups. 


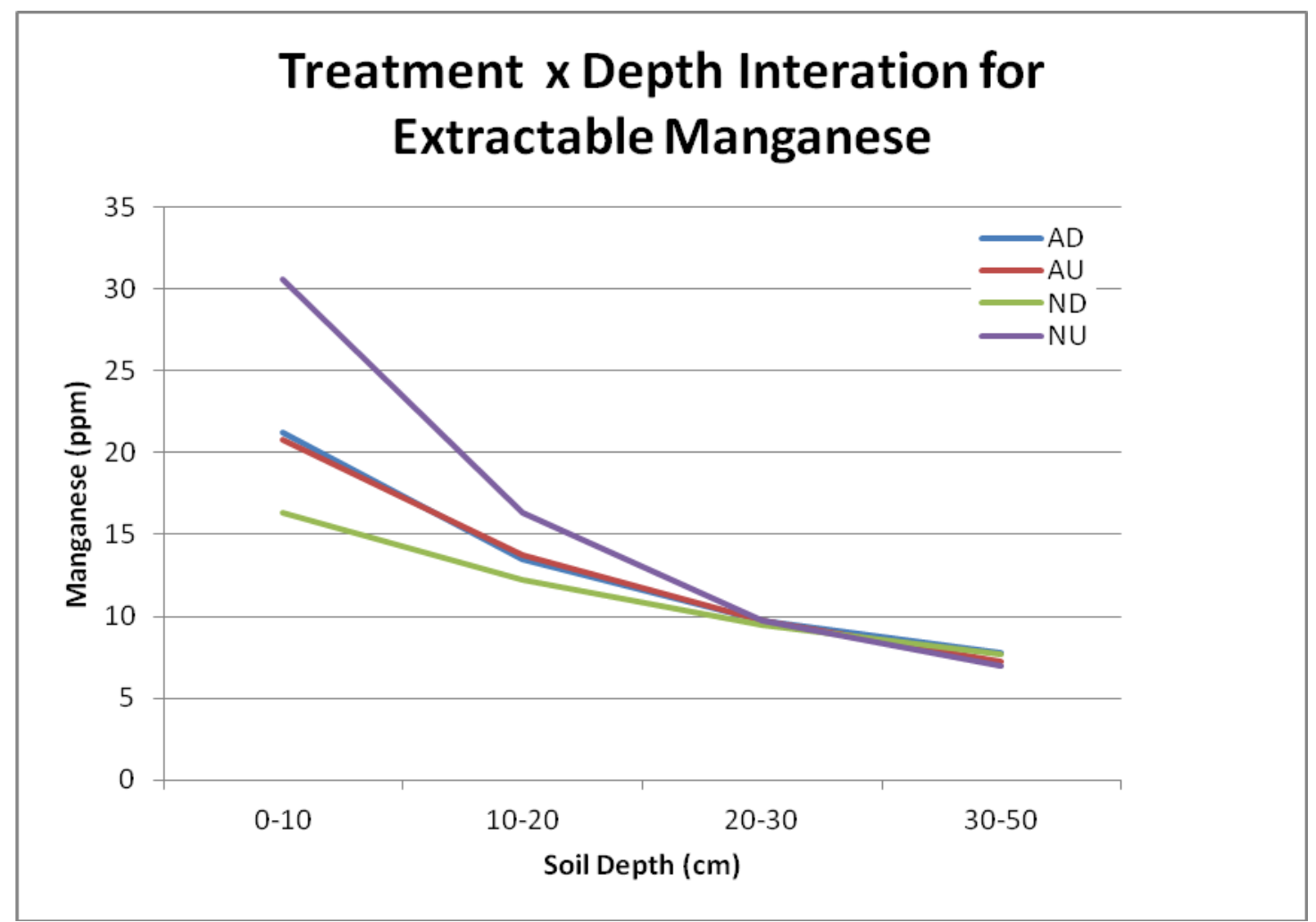

Figure 7. Extractable manganese concentration with depth from disturbed (D) and undisturbed (U) archaeological (A) and non-archaeological (N) treatment groups.

\subsection{Total Phosphorus}

Although the amount of total phosphorus in average mineral soils compares favorably to that of nitrogen, it is much lower than calcium or magnesium. However, most soil phosphorus is unavailable to plants and limits growth. To overcome this problem, most soils in the US used for agricultural or timber production have been extensively fertilized with phosphorus containing fertilizers. Because much of this fertilizer supplied phosphorus can be quickly "fixed" by soils and rendered unavailable to plants, phosphorus application rates have been quite high to compensate for this fixation. This repeated and often undocumented phosphorus fertilization, coupled with low removal rates by plants, has resulted in an abundance of total phosphorus in soils. Although the significant treatment by depth interaction for total phosphorus across installations (Figure 8) suggests that this variable responds differentially according to disturbance, the abundance of total phosphorus in soils, especially those which have been used for timber and agronomic production, probably limits the practical use of this variable as an indicator of severity and depth of disturbance relative to archaeological resources. 


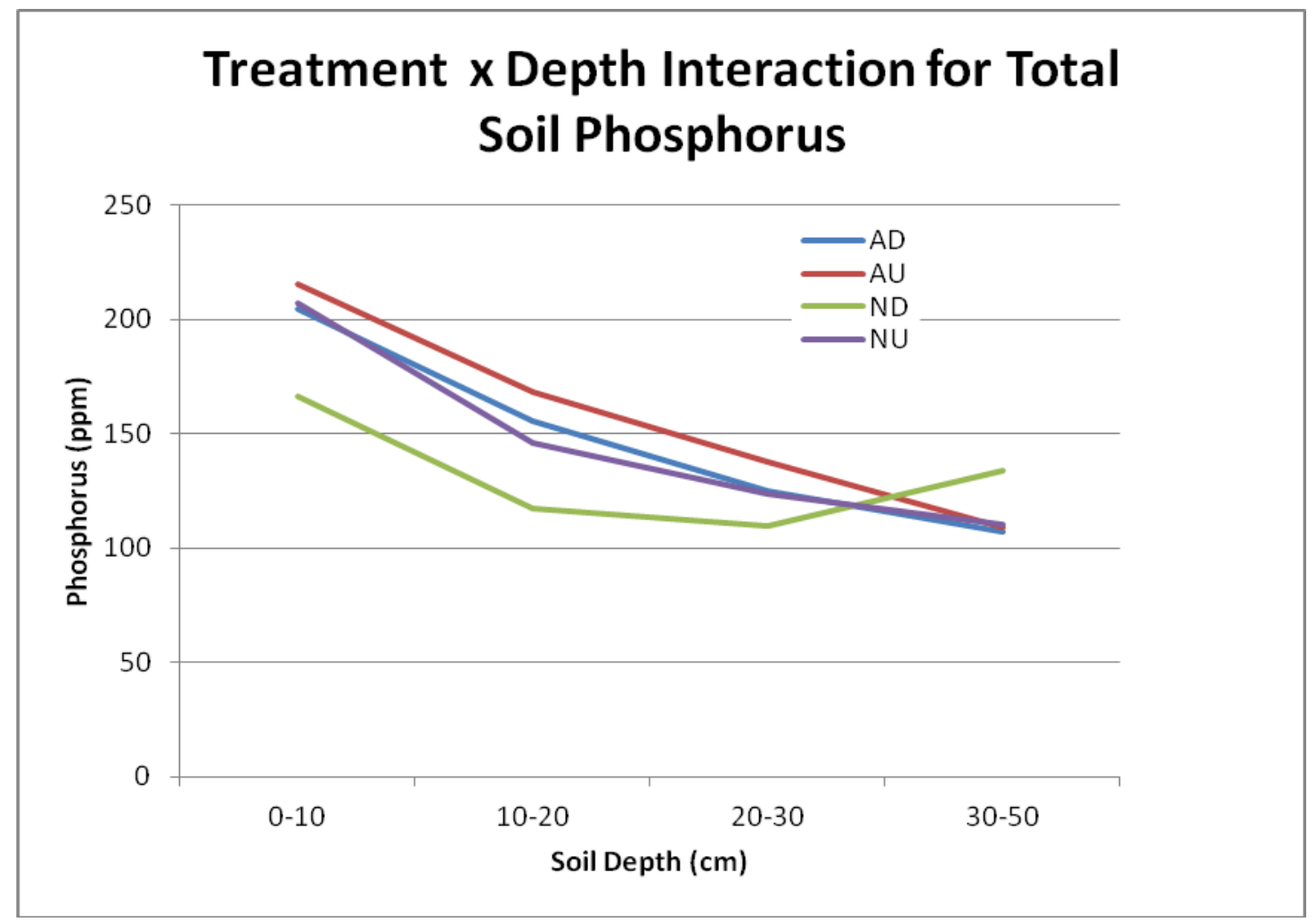

Figure 8. Total phosphorus concentration with depth from disturbed (D) and undisturbed (U) archaeological (A) and non-archaeological (N) treatment groups.

\subsection{Ratios}

Because of the reliable and well established vertical distributions of soil carbon with respect to disturbance (Torbert, 2004), the project team initiated evaluation of a series of ratios using soil carbon, extractable, and/or total soil metals in an attempt to highlight potential indicators of disturbance that may be more stable across varying soil types and geographic gradients. These types of ratios were considered potentially useful disturbance indicators as they would reflect recent (days to weeks) disturbance, based on changes in metal distributions, as well as longer timeframe (weeks to months) disturbances based on changes in soil carbon distributions. Other ratios of interest that may improve the stability and reliability of potential disturbance indicators across multiple soil types and geographic gradients include top-to-total metal concentrations, extractable-to-total metal concentrations, and simple elemental ratios. The concepts behind these ratios and some preliminary examples are discussed in the following sections.

Ratios of soil element concentrations have been used to develop soil process relationships that are applicable across multiple soil types and climate conditions. One of the better known and widely used of these ratios is the one between soil carbon and nitrogen. Soil carbon concentrations can be extremely variable across soil types, however, despite these large differences, the $\mathrm{C}: \mathrm{N}$ ratio can be used to determine the basic levels of decomposition, mineralization, and immobilization processes that impact soil fertility and plant growth. Most soils in equilibrium will have a $\mathrm{C}: \mathrm{N}$ ratio in the range of 10-12. Ratios 
above this indicate a recent influx of organic carbon into the system and elevated soil microbial activity. Rapid changes in C:N are commonly the result of tillage or some other disturbance and have important implications for soil fertility and plant production. Because the $\mathrm{C}: \mathrm{N}$ ratio tends to normalize values across soil types and climatic regimes, our research team began initially investigating other types of soil property ratios that may serve as disturbance indicators and have implications for archaeological integrity.

\subsubsection{Top-to-Total Ratio}

One ratio of interest is the top-to-total ratio, which is the ratio of a given soil element concentration in the top $10 \mathrm{~cm}$ of the profile to the concentration of that element in the entire $50 \mathrm{~cm}$ profile (e.g. potassium in top $10 \mathrm{~cm}$ of profile : potassium in total $50 \mathrm{~cm}$ of profile). Natural soil forming processes lead to the development of soil layers, each having distinctive concentrations of soil elements that contribute to the overall vertical distribution pattern within the entire soil profile. Soil disturbance that results in soil mixing will consequently change the distribution of these elements with soil depth. Concentrations of any given soil element would be expected to change dramatically across different soil types, however, within soil types the concentration and vertical distribution patterns would be consistent. Therefore, any change in vertical distribution for a given soil element (especially a stable soil element) would be a clear indication that disturbance has resulted in soil mixing. The ratio of concentration in the top $10 \mathrm{~cm}$ to the total concentration in the soil profile is an attempt to normalize changes in absolute soil concentrations and develop a more standardized measure of soil mixing.

An example of this ratio is presented for Fort Benning, where the sandy nature of the soils makes them vulnerable to deep mixing. Significant top-to-total ratios were observed for total phosphorus $(p=0.005)$ and total sulfur ( $p=0.001)$ averaged over all sampled sites at Fort Benning (Figure 9). The change in the top-to-total ratios with disturbance clearly indicates that mixing has occurred and that this relationship holds promise as a measure that can indicate soil disturbance, especially if constructed using previously identified soil variables which exhibit significant treatment by depth interactions across multiple sites (i.e. extractable nickel, calcium, magnesium, manganese, total phosphorus, $\mathrm{pH}$, carbon). 


\section{Top-to-Total Ratio}

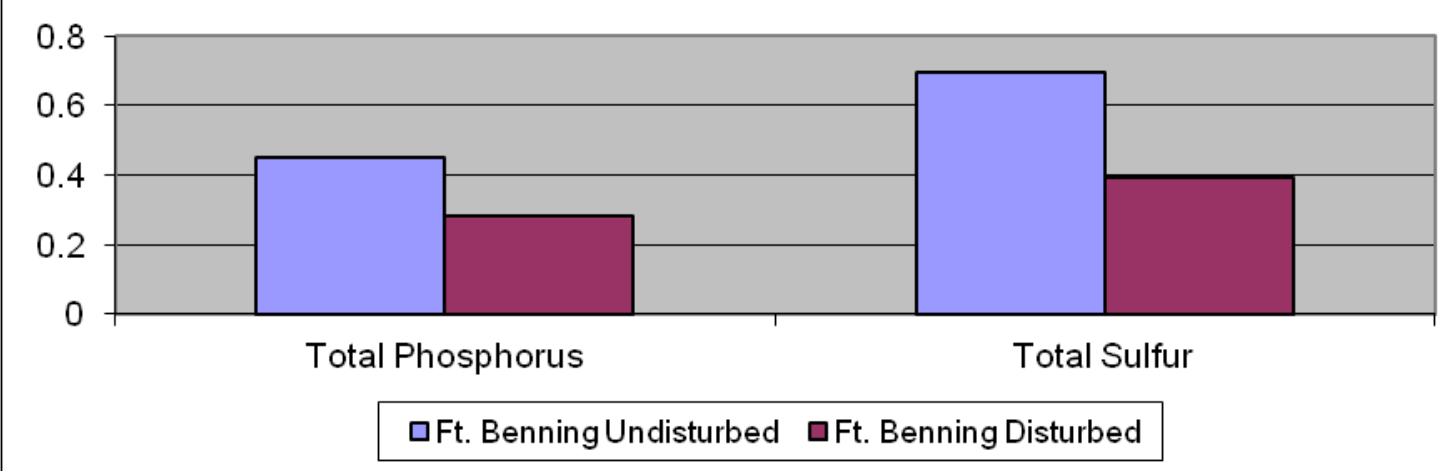

Figure 9. Ratio of total phosphorus and total sulfur concentrations in the upper $10 \mathrm{~cm}$ to the respective concentrations in the entire $50 \mathrm{~cm}$ soil profile.

\subsubsection{Total-to-Soluble Ratio}

Another ratio of interest is the total-to-soluble ratio, which is the ratio of the total element concentration to the extractable or soluble element concentration. All soils are subject to mineralogical weathering processes that convert insoluble elements/compounds to more soluble forms over time. This weathering process is fundamental to soil formation and leads to the development of soil layers with distinct elemental signatures that contribute to the overall vertical distribution pattern of elements within the entire soil profile. Over time, soil weathering processes reach an equilibrium state in any given soil that will be disrupted with disturbance. In addition to the actual physical disturbance, changes in soil surface area, soil moisture levels, pore space distributions, and microbial activity will alter the mineralogical weathering processes, causing changes in the concentration of soluble elements. Total and soluble concentrations of any given soil element would be expected to differ dramatically across dissimilar soil types, however, within soil types the concentration and vertical distribution patterns would be consistent. Therefore, any change in the ratio of total-to-soluble soil element concentration would be a clear indicator that mineralogical weathering processes have been altered and that disturbance is likely responsible. Since mineralogical weathering processes take place over longer time frames, any change in the total-to-soluble ratio would be a long term indicator of soil disturbance. Furthermore, these changes would seem to be a more sensitive measure of soil disturbance than could be expected from the changes in total or soluble elemental concentrations when considered alone.

An example of this total-to-soluble ratio is presented for Fort Riley, where the more complex mineralogy and age of the soils provided higher total and soluble concentrations of many elements, thereby enabling this relationship to be fully demonstrated. Significant total-to-soluble ratios were observed for both calcium $(p=0.017)$ and potassium $(p=0.048)$ when averaged over all sites at Fort Riley (Figure 10). The modest, but significant changes in the total-to-soluble ratio with disturbance clearly indicates that changes are detectable and that this relationship holds promise as a measure that can indicate soil 
disturbance over time, especially if constructed using previously identified soil variables which exhibit significant treatment by depth interactions across multiple sites (i.e. extractable nickel, calcium, magnesium, manganese, total phosphorus, $\mathrm{pH}$, carbon).

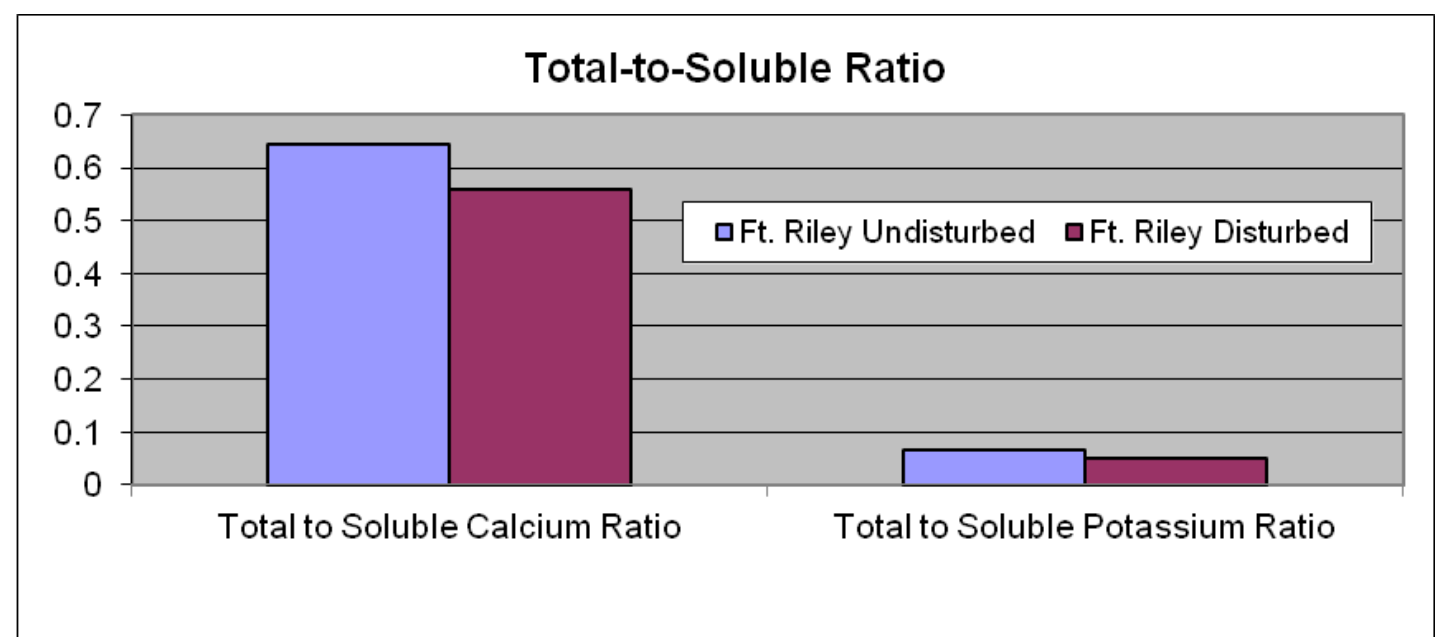

Figure 10. Ratio of total-to-soluble calcium and potassium concentrations at Fort Riley, $\mathrm{KS}$, in the $0-10 \mathrm{~cm}$ depth increment.

\subsubsection{Leachable-to-Nonleachable Ratio}

Another ratio of interest is the leachable-to-nonleachable ratio, which is the ratio between elements that are considered leachable or mobile to those elements that are considered nonleachable or immobile. Due to mineralogical weathering processes present during soil development, soil elements and compounds distribute themselves in the soil profile as a function of their leaching potential. These weathering processes are fundamental to soil formation and lead to the development of soil layers with distinct elemental signatures that contribute to the overall vertical distribution pattern of elements within the entire soil profile. Over time, soil weathering processes reach an equilibrium state in any given soil that will be disrupted with disturbance, causing physical mixing, displacement of elements in the soil profile, and alterations in mineralization processes which affect the leachable element concentration in soil solution. Leachable and nonleachable element concentrations would be expected to differ significantly across dissimilar soil types, however, within soil types the concentration and vertical distribution patterns would be consistent. Therefore, any change in the ratio of leachable-to-nonleachable soil element concentrations may be a potential indicator of disturbance and depth of disturbance. The ratio between leachable and nonleachable elemental concentrations at various depths is an attempt to normalize changes in absolute soil concentrations and would seem to be a more sensitive measure of soil disturbance than could be expected from the changes in leachable or nonleachable elemental concentrations when considered individually.

An example of this leaching to non-leaching element ratio is presented for both Fort Benning and Fort Riley. Significant $(p<0.05)$ leachable-to-nonleachable element ratios were observed for potassium (leachable) to total iron (nonleachable) and sulfur (leachable) to total iron for soil disturbance averaged across all sites at each installation (Figure 
11). The change in the ratio with disturbance clearly indicates that a change in the leachable-to-nonleachable element concentrations has occurred and that this relationship holds promise as a measure that can indicate soil disturbance and depth of disturbance, especially if constructed using previously identified soil variables which exhibit significant treatment by depth interactions across multiple sites (i.e. extractable nickel, calcium, magnesium, manganese, total phosphorus, $\mathrm{pH}$, carbon).

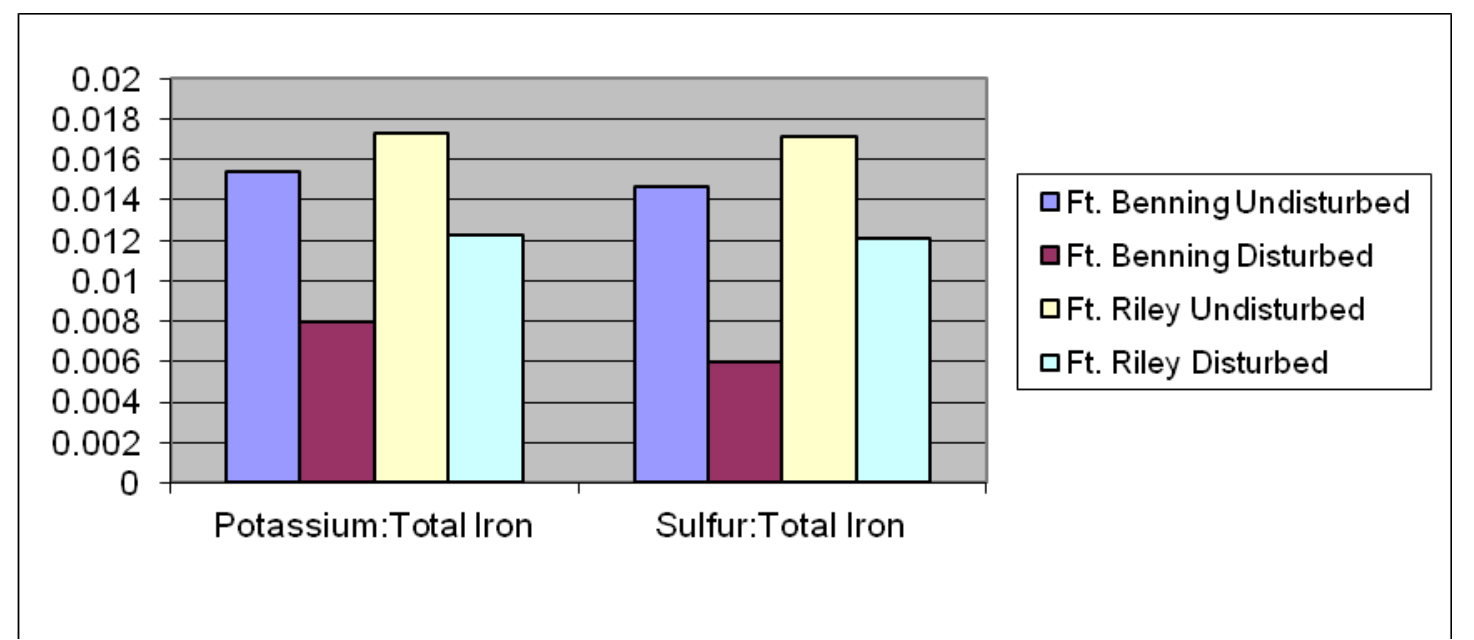

Figure 11. Ratio of leachable (potassium and sulfur) to nonleachable (total iron) element concentrations at Fort Benning, GA, and Fort Riley, KS, in the 0-10 cm depth increment.

\subsubsection{Soil Variables Removed From Consideration}

Many soil variables collected for consideration as potential indicators of disturbance for this research project showed excessive variation within and between installations, experimental sites, and treatment groups and were eliminated from further consideration. Out of the 37 soil variables considered, only the seven previously discussed exhibited significant treatment by depth interactions across installations, suggesting potential use as indicators of disturbance based on a differential vertical distribution relative to disturbance treatment group. The remaining 30 excluded from consideration included extractable $\mathrm{Al}$, $\mathrm{B}, \mathrm{Cd}, \mathrm{Cr}, \mathrm{Cu}, \mathrm{Fe}, \mathrm{K}, \mathrm{Mo}, \mathrm{Na}, \mathrm{P}, \mathrm{Pb}$, and Zn; Total N, K, Ca, Mg, S, Mn, Fe, Al, B, Cu, $\mathrm{Zn}, \mathrm{Na}, \mathrm{Ni}, \mathrm{Pb}$, and $\mathrm{Cr}$; water equivalent $\mathrm{pH}$; lime buffering capacity (LBC); and cation exchange capacity (CEC).

\subsection{Dose/Response Transect, Fort Riley, KS}

The dose/response transect was established on a Wymore soil series, the same soil series that sites 195 and 1173 occurred upon. With the exception of soil pH, comparison of soil variable data between the dose/response transect and sites 195 and 1173 indicated that all values were within the normal range for Wymore soils and no extreme outliers were noted. Soil $\mathrm{pH}$ for the dose/response transect increased slightly from about 6.1 to 6.9 with depth $(0-50 \mathrm{~cm})$ for the undisturbed sections, whereas it decreased from about 6.9 to 5.5 with depth on sites 195 and 1173. Past land management, agricultural production, and 
fertilization/liming practices were likely the cause of these differences, however, historic records detailing agricultural production practices do not exist for any of the locations.

Dose/response transects were designed to evaluate changes in the vertical distribution of selected soil variables due to repeated tank traffic. As level of traffic disturbance increased, it was expected that changes in the vertical distribution of some soil variables could be used to estimate depth of disturbance on a somewhat predictable basis. For the previously identified variables showing promise as indicators of disturbance across wide geographic and edaphic ranges, total phosphorus, extractable calcium, and extractable manganese exhibited changes in distribution with depth as levels of tank traffic increased, suggesting that mixing to depths of $10-30 \mathrm{~cm}$ could be inferred. Figure 12 depicts the depth distribution changes in total phosphorus that occurred with increasing tank traffic. At 8-9 tank passes, values for total phosphorus at each depth increment converged, suggesting significant mixing had occurred at depths of $30-50 \mathrm{~cm}$. A similar trend was seen for extractable calcium (Figure 13), where 5-7 tank passes resulted in a convergence of values at each depth increment that would be suggestive of mixing to depths approaching $30 \mathrm{~cm}$. Extractable manganese in the $0-10 \mathrm{~cm}$ depth increment was lower than that for the 10-20 and 20-30 cm depth increments suggesting mixing to depths of 20-30 cm (Figure 14). At Fort Riley, KS, where A/B horizon interfaces of common soil series occur between $13-30 \mathrm{~cm}$, this disturbance depth may be significant for cultural resources below the Ap horizon. Caution should be exercised, however, in interpreting these data as only two soil cores were collected for each tank traffic pass along the transect, thereby precluding robust statistical analyses.

For the previously identified variables showing promise as indicators of disturbance across wide geographic and edaphic ranges, soil $\mathrm{pH}$ and extractable magnesium exhibited similar changes in distribution with depth as levels of tank traffic increased (Figures 15 and 16). Distribution patterns were similar with respect to tank traffic for each depth increment, indicating that these data could not be used to infer soil depth increment mixing due to disturbance/traffic. The interaction of extractable nickel between the $0-10 \mathrm{~cm}$ and 10-20 cm depth increments at 5-7 tank passes is somewhat suggestive of mixing to depths of 10-20 cm (Figure 17), but as with total phosphorus, extractable calcium, and extractable manganese, caution should be exercised in interpreting these data as only two soil cores were collected for each tank traffic pass along the transect. 


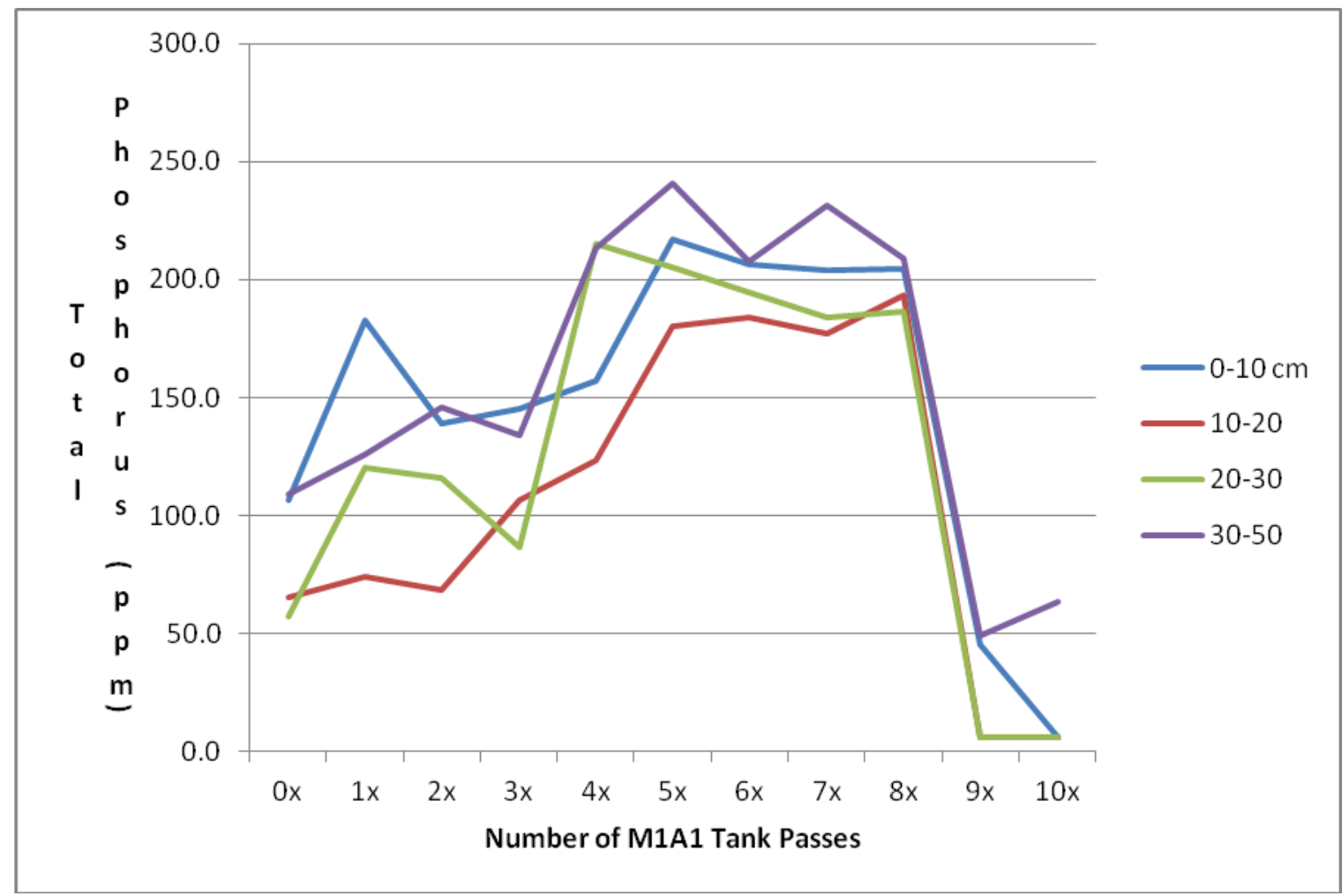

Figure 12. Total phosphorus depth distribution in a Wymore soil profile as a function of increasing numbers of passes by an M1A1 tank.

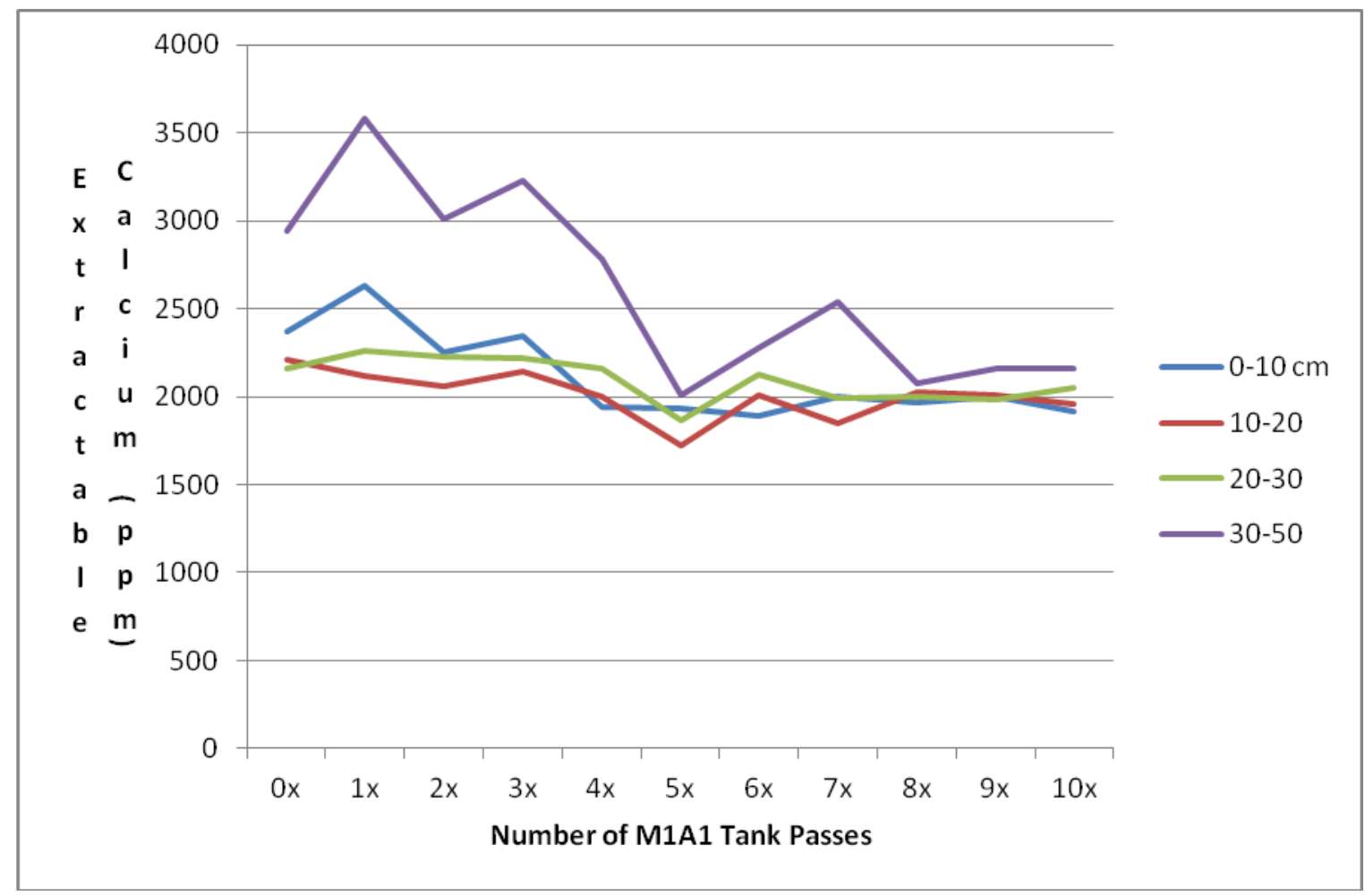

Figure 13. Extractable calcium depth distribution in a Wymore soil profile as a function of increasing numbers of passes by an M1A1 tank. 


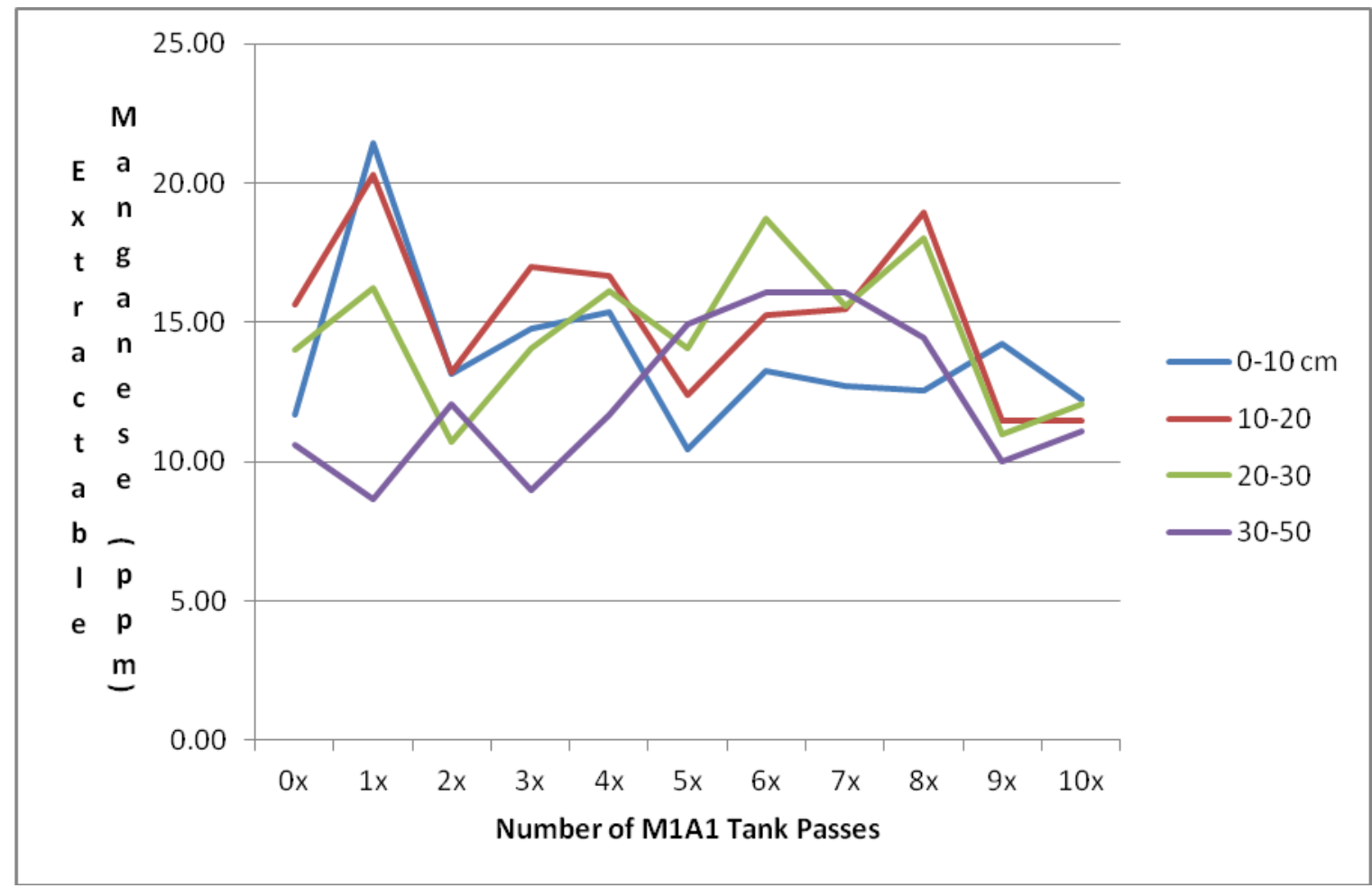

Figure 14. Extractable manganese depth distribution in a Wymore soil profile as a function of increasing numbers of passes by an M1A1 tank.

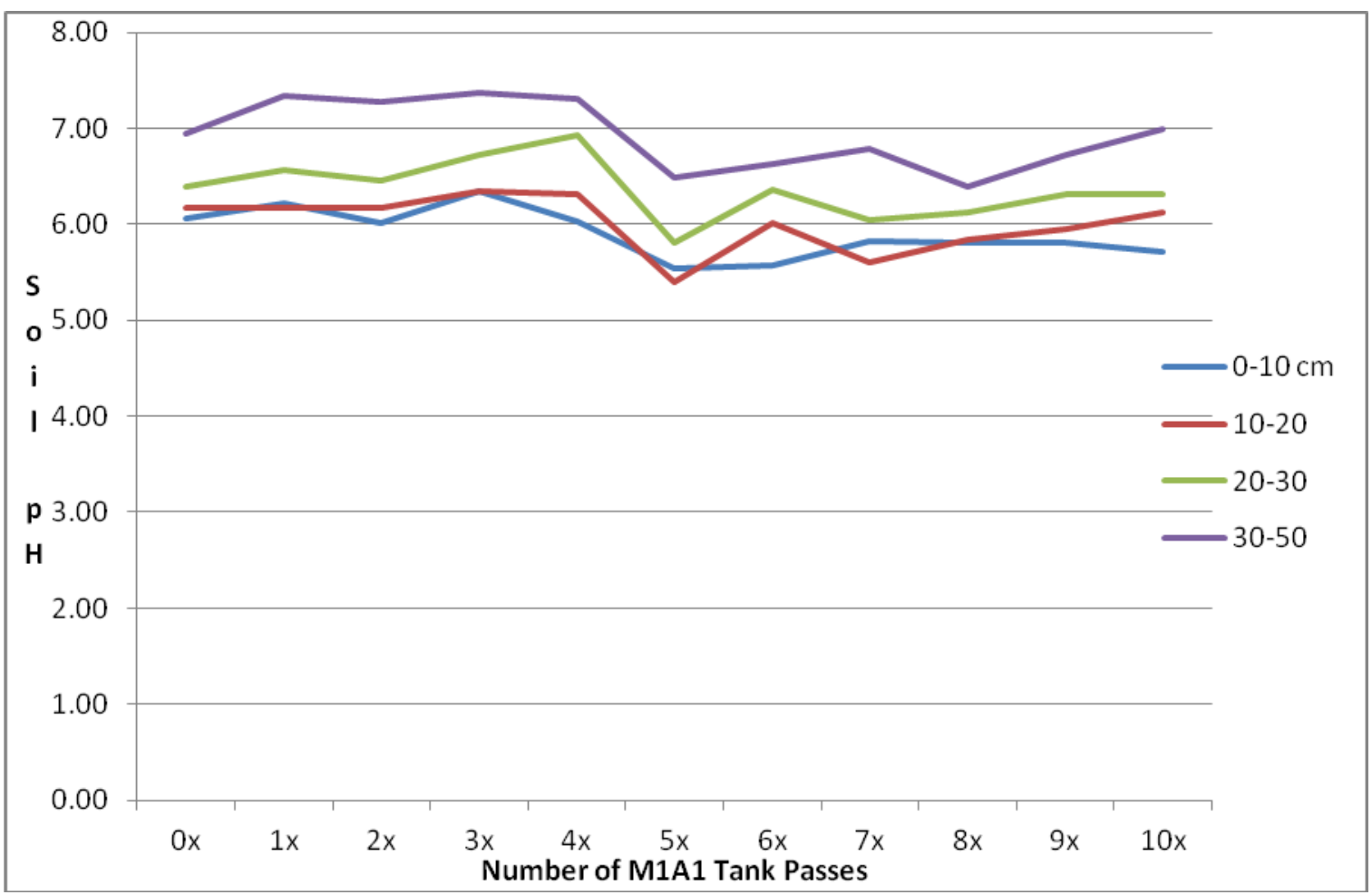

Figure 15. Soil pH depth distribution in a Wymore soil profile as a function of increasing numbers of passes by an M1A1 tank. 


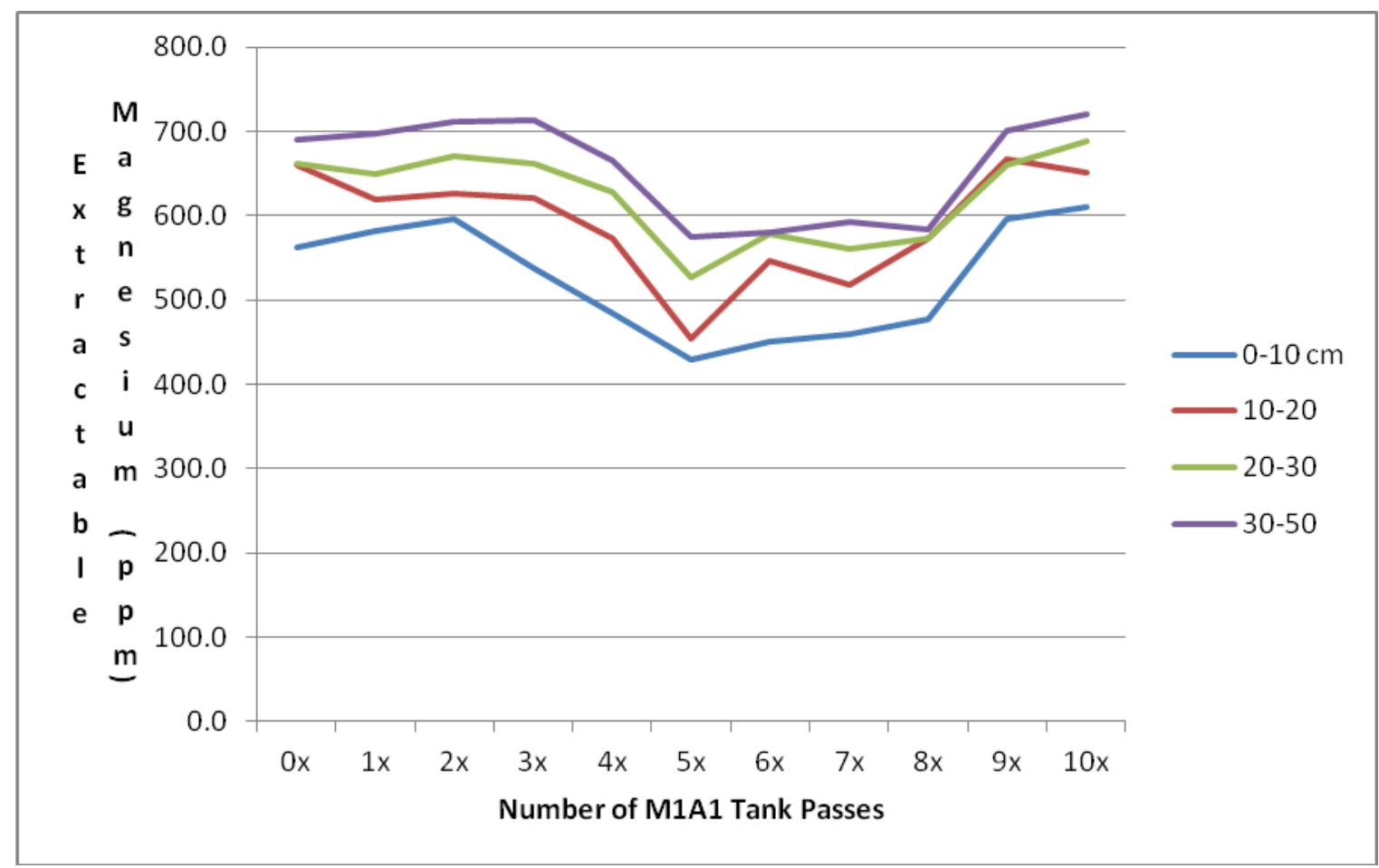

Figure 16. Extractable magnesium depth distribution in a Wymore soil profile as a function of increasing numbers of passes by an M1A1 tank.

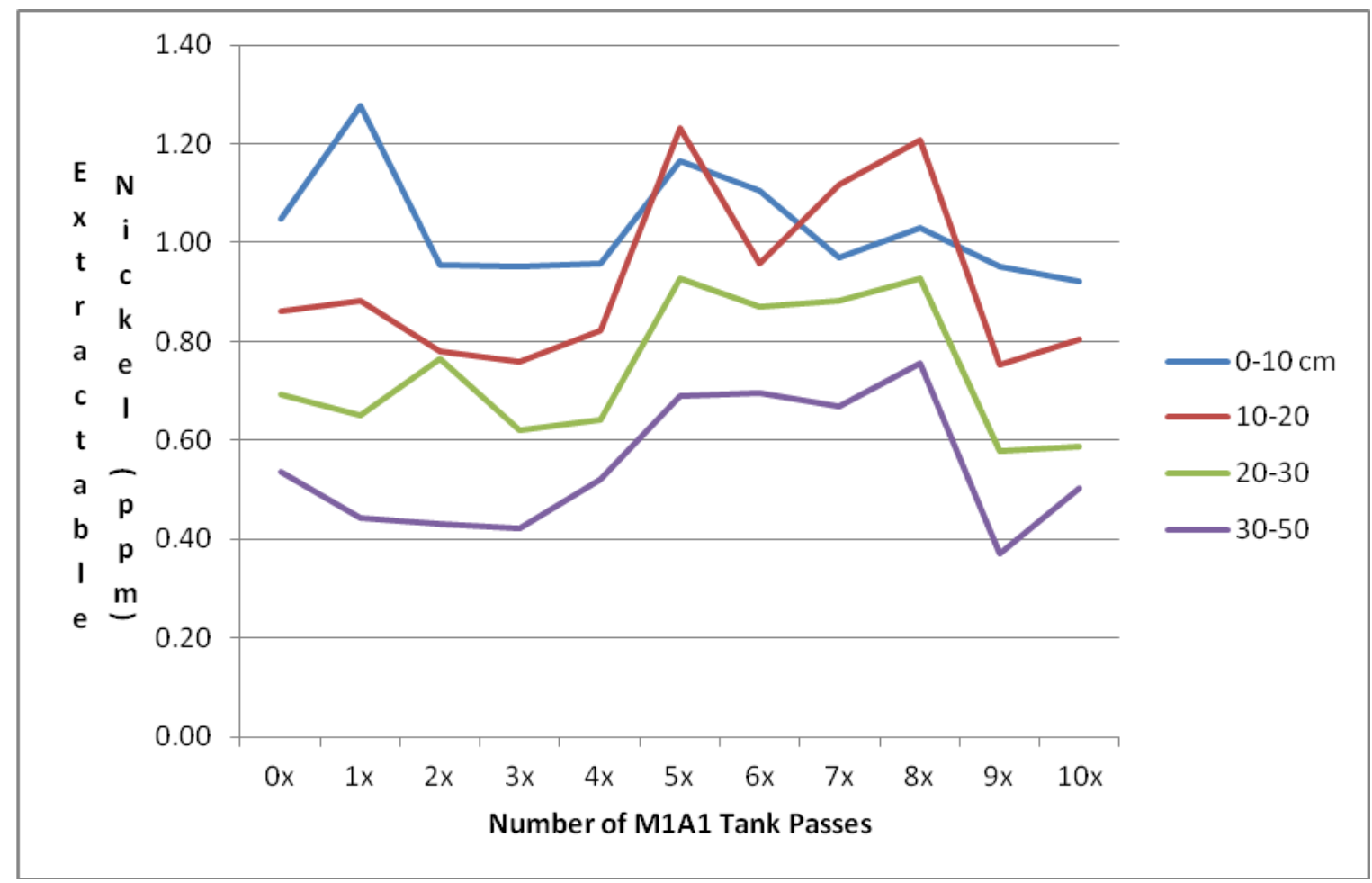

Figure 17. Extractable nickel depth distribution in a Wymore soil profile as a function of increasing numbers of passes by an M1A1 tank. 


\section{CONCLUSIONS AND IMPLICATIONS FOR FUTURE RESEARCH}

Soil carbon concentrations were always negatively impacted in disturbed treatment group soils, indicating that carbon is a reliable indicator of disturbance. Although soil organic carbon content is a predictable indicator of disturbance, its use as an indicator of both severity and depth of disturbance may be enhanced when used in combination or ratio with other metallic soil elements such as nickel, zinc, chromium, or lead which accumulate in undisturbed surface soil horizons.

Soil $\mathrm{pH}$, and extractable calcium, magnesium, and manganese were generally lower for disturbed treatment groups to depths of 10 to $20 \mathrm{~cm}$ when compared to undisturbed treatment groups. Use of soil $\mathrm{pH}$ as a sole indicator of disturbance would be inadvisable due to agricultural and timber production practices, such as liming and fertilization, which can quickly change $\mathrm{pH}$ in surface soils. The predictable decreases in soil $\mathrm{pH}$ with disturbance, however, suggest that use of soil $\mathrm{pH}$ in combination or ratio with other variables such as organic carbon or metallic elements may provide evidence to ascertain severity and depth of disturbance. Treatment by depth interactions for extractable calcium, magnesium, and manganese suggest that these variables exhibit similar distribution by depth patterns irrespective of treatment group and are probably not particularly useful as indicators of severity or depth of disturbance. This is not unexpected given that these elements are so common in most soils, but does not preclude their use in ratios with other variables such as $\mathrm{pH}$ or soil organic carbon where the ability to detect severity and depth of disturbance may be enhanced.

Extractable nickel concentrations were generally higher for disturbed treatment groups to depths of 10-30 cm when compared to undisturbed treatment groups, suggesting that extractable nickel concentrations may be useful for documenting disturbance and estimating depth of disturbance in soils with high natural levels of nickel. Undisturbed treatment groups exhibited increases in nickel concentration in the 0-30 cm depth increment, while disturbed treatment groups showed general declines to depths of $30 \mathrm{~cm}$, suggesting that this divergent distribution pattern with depth may be a potential indicator of disturbance and depth of disturbance, warranting additional research.

Although the soil variables discussed above show promise as potential indicators of both depth and degree of disturbance, it is important to note that site characteristics such as vegetation cover and composition, soil structure, and soil moisture dynamics can be altered by disturbance to the extent that differences between treatment groups may be confounded by these site characteristics. For example, if disturbance is frequent and severe in nature, wholesale changes in the plant community composition may occur between disturbed and undisturbed sites, resulting in plant communities dominated by annual species and perennial species or grass/forb and shrub/tree species on disturbed and undisturbed sites, respectively. These gross differences in plant community composition can differentially affect plant nutrient uptake, assimilation, deposition, and decomposition between disturbed and undisturbed sites, which could confound differences between treatment groups. For the major plant macronutrients, such as N, P, and K, the differences observed in surface and shallow soil depth increments between disturbed and un- 
disturbed sites due to plant community composition could be significant, but would likely differ only in terms of magnitude and not distribution with depth. Differences observed for micronutrients and trace elements, such as $\mathrm{Mn}$ and $\mathrm{Ni}$, would be expected to be much smaller as these elements are tightly bound by soil particles and organic matter, and only assimilated in very small quantities irrespective of plant community composition.

Site disturbance can also alter soil structure and the ability of soils to bind nutrients. Macroaggregates are quickly degraded with soil disturbance, resulting in relatively rapid mineralization of bound nutrients which could also exacerbate observed differences between disturbed and undisturbed treatment groups. Differences between disturbed and undisturbed soil depth increment samples due to macroaggregate degradation and nutrient mineralization would be expected to vary only in terms of magnitude with depth, unless the disturbance resulted in soil horizon inversion or burial, thereby changing not only magnitude but vertical distribution of the soil nutrients as well. Under the conditions of severe disturbance (burial or inversion of soil horizons) whereby soil structure is disrupted with an attendant increase in nutrient mineralization, these changes in soil structure may improve the ability to detect depth of disturbance due to exaggerated changes in the vertical distribution patterns between disturbed and undisturbed sites.

As previously discussed, site disturbance can impact plant community cover, plant community composition, and soil structure, which can bias observed differences between disturbed and undisturbed treatment groups. Differences in plant community cover, composition, and soil structure also impact interception, infiltration, and percolation of precipitation as well as soil water holding capacity, which ultimately impacts nutrient uptake and removal within the soil profile. These impacts would be especially important for readily soluble nutrients such as $\mathrm{N}$ and $\mathrm{K}$, resulting in potentially large differences between disturbed and undisturbed treatment groups within a given soil depth increment. Differences for relatively insoluble micronutrients/elements or those bound tightly to soil particles and organic matter, such as $\mathrm{Mn}$ and $\mathrm{Ni}$, would be expected to be much smaller in magnitude, however. Under conditions of severe disturbance, where soil horizons are buried or inverted, these potential differences in nutrient transport due to soil moisture may improve the ability to detect depth of disturbance because of differences seen in the vertical distribution patterns between disturbed and undisturbed sites.

The potentially confounding effects of plant community, soil structure, and soil moisture on being able to detect meaningful differences between disturbed and undisturbed treatment groups illustrates the need to assure that sampling sites occur on the same soil series and in relatively close proximity to one another. Disturbance has been shown to alter plant community composition, which in turn will affect nutrient distribution according to above- and below-ground biomass production, nutrient uptake and assimilation, and biomass turnover and decomposition. Disturbance has been shown to modify soil moisture content and soil profile water distribution, which influences nutrient distribution. Soil disturbance has also been shown to change soil structure, which in turn may impact nutrient distribution. However, by ensuring that disturbed and undisturbed treatment groups occur on the same soil series, the influence of disturbance-induced changes in soil moisture, soil texture, soil structure, and plant community can be minimized, and the impacts 
of training disturbance on elemental distribution within the soil profile can be maximized. It is imperative to establish soil series identification using established soil mapping and identification protocols, and subsequent comparison to USDA-NRCS soil maps, in order to accurately determine appropriate disturbed and undisturbed treatment groups for comparison.

As previously discussed, the use of soil $\mathrm{pH}$, soil organic carbon, extractable nickel, calcium, magnesium, and manganese, concentrations as indicators of both severity and depth of disturbance may be enhanced when used in combination or ratio with any number of other soil variables, including organic carbon, zinc, chromium, lead, etc.

The recognition that ratios or combinations of soil variables might be more stable indicators of disturbance across wide geographic and edaphic ranges than single variables led to the development of several small-scale validation tests involving the concept of top-tototal ratios, total-to-soluble ratios, and leachable-to-nonleachable elemental ratios. Significant top-to-total ratios were observed for total phosphorus and total sulfur averaged over all sampled sites at Fort Benning, GA. The change in the top-to-total ratios with disturbance clearly indicates that mixing has occurred and that this relationship holds promise as a measure that can indicate soil disturbance, especially if constructed using previously identified soil variables that exhibit significant treatment by depth interactions across multiple sites (i.e., extractable nickel, calcium, magnesium, manganese, total phosphorus, $\mathrm{pH}$, carbon). With the exception of developing top-to-total ratios for phosphorus and sulfur at Fort Benning, GA, this type of ratio was not extensively developed or tested on other data.

Significant total-to-soluble ratios were observed for both calcium and potassium when averaged over all sites at Fort Riley, KS. The modest but significant changes in the totalto-soluble ratio with disturbance clearly indicates that changes are detectable and that this relationship holds promise as a measure that can indicate soil disturbance over time, especially if constructed using previously identified soil variables that exhibit significant treatment by depth interactions across multiple sites (i.e. extractable nickel, calcium, magnesium, manganese, total phosphorus, $\mathrm{pH}$, carbon). With the exception of developing total-to-soluble ratios for calcium and potassium at Fort Riley, KS, this type of ratio was not extensively developed or tested on the entire data set.

Significant leachable-to-nonleachable element ratios were observed for potassium (leachable) to total iron (nonleachable) and sulfur (leachable) to total iron (nonleachable) for soil disturbance averaged across all sites at both Fort Riley, KS, and Fort Benning, GA. The change in the ratio with disturbance clearly indicates that a change in the leachableto-nonleachable element concentrations has occurred and that this relationship holds promise as a measure that can indicate soil disturbance and depth of disturbance, especially if constructed using previously identified soil variables that exhibit significant treatment by depth interactions across multiple sites (i.e., extractable nickel, calcium, magnesium, manganese, total phosphorus, $\mathrm{pH}$, carbon). With the exception of developing leachable-to-nonleachable ratios for potassium:iron and sulfur:iron at both installations, these types of ratios were not extensively developed or tested on the entire data set. 
At Fort Riley, KS, data collected from the dose/response transect was used to test the concept of using soil variables to estimate the effects of tank traffic "dose" on soil variable "response" as a means to evaluate depth of disturbance. For the previously identified variables showing promise as indicators of disturbance across wide geographic and edaphic ranges, total phosphorus, extractable calcium, and extractable manganese exhibited changes in distribution with depth as levels of tank traffic increased, suggesting that mixing to depths of 10-30 cm could be inferred. Figure 12 depicts the depth distribution changes in total phosphorus that occurred with increasing numbers of tank traffic. At 8-9 tank passes, values for total phosphorus at each depth increment converged, suggesting significant mixing had occurred at depths of $30-50 \mathrm{~cm}$. A similar trend was seen for extractable calcium (Figure 13), where 5-7 tank passes resulted in a convergence of values at each depth increment that would be suggestive of mixing to depths approaching $30 \mathrm{~cm}$. Extractable manganese in the $0-10 \mathrm{~cm}$ depth increment was lower than that for the 10-20 and 20-30 cm depth increments, suggesting mixing to depths of 20-30 cm (Figure 14). At Fort Riley, KS, where A/B horizon interfaces of common soil series occur between 13-30 cm, this disturbance depth may be significant for cultural resources below the Ap horizon. Caution should be exercised, however, in interpreting these data as only two soil cores were collected for each tank traffic pass along the transect, thereby precluding robust statistical analyses.

For the previously identified variables showing promise as indicators of disturbance across wide geographic and edaphic ranges, soil $\mathrm{pH}$ and extractable magnesium exhibited similar changes in distribution with depth as levels of tank traffic increased (Figures 15 and 16). Distribution patterns were similar with respect to tank traffic for each depth increment, indicating that these data could not be used to infer soil depth increment mixing due to disturbance/traffic. The interaction of extractable nickel between the $0-10 \mathrm{~cm}$ and 10-20 cm depth increments at 5-7 tank passes is somewhat suggestive of mixing to depths of 10-20 cm (Figure 17), but as with total phosphorus, extractable calcium, and extractable manganese, caution should be exercised in interpreting these data as only two soil cores were collected for each tank traffic pass along the transect. However, the trends seen for extractable nickel, total phosphorus, extractable calcium, and extractable manganese with increasing levels of disturbance suggest that continued research may be fruitful. 


\section{LITERATURE CITED}

Ahler, Stanley A. 1973. A chemical analysis of deposits at Rogers Rock Shelter, Missouri. Plains Anthropologist 18, pp. 116-131

Ayers, P. 1994. Environmental damage from tracked vehicle operation. Journal of Terramechanics 31(3):173-183.

Ayers P., R. Shaw, V. Diersing, and J. Van Riper. 1990. Soil compaction from military vehicles. ASAE Paper No. 90-1096, St. Joseph, MI

Boyer, J.N., and P.M. Groffman. 1996. Bioavailability of water extractable organic carbon fractions in forest and agricultural soil profiles. Soil Biology and Biochemistry 28:783-790

Brady, N.C. 1974. The Nature and Properties of Soils, 8th Edition. Macmillan Publishing Co., Inc. New York

Cohen, J. 1988. Statistical Power Analysis for the Behavioral Sciences. (2nd ed.) ISBN 0-8058-0283-5.

Curath, Amy, Kenny Pearce, Warren Curruth, Klint Baggett, Tom Carty, and Paul Jackson. 2008. Phase II Investigation of 48 Sites. Good Hope Heavy Maneuver Area, Driver Training, and Vehicle Recovery Areas, and Fire and Maneuver Range 3, Fort Benning Military Reservation, Chattahoochee and Muscogee Counties, Georgia. Report submitted to the Department of the Army, Headquarters, United States Army Infantry Center, Fort Benning. Panamerican Consultants, Inc., Tuscaloosa, Alabama.

Davidson, D.A. 1973. Particle size and phosphate analysis. Evidence for the evolution of a tell. Archaeometry 15 pp. 143-52.

Davidson, E.A., and I.L. Ackerman. 1993. Changes in soil carbon inventories following cultivation of previously untilled soils. Biogeochemistry 20:161-193.

Elliott, E.T. 1986. Aggregate structure and carbon, nitrogen, and phosphorus in native and cultivated soils. Soil Science Society of America Journal 50:627-633.

Entwistle, Jane A., Peter W. Abrahams, and R.A. Dodgshon. 1998. Multi-element analysis of soils from Scottish historical sites. Interpreting land-use history through he physical and geochemical analysis of soil. Journal of Archaeological Science 25:53-68.

Entwistle, Jane A., Peter W. Abrahams, and R.A. Dodgshon. 2000a. The geoarchaeological significance and spatial variability of a range of physical and 
chemical soil properties from a former habitation site, Isle of Skye. Journal of Archaeological Science 27:287-303.

Entwistle, Jane A., R.A. Dodgshon, and P.W. Abrahams. 2000b. An investigation of former land-use activity through physical and chemical analysis of soils from the Isle of Lewis, Outer Hebrides. Archaeological Prospection 7:171-188.

Franzluebbers, A.J. 2002. Soil organic matter stratification ratio as an indicator of soil quality. Soil and Tillage Research 66:95-106.

Gebhart, D.L., H.B. Johnson, H.S. Mayeux, and H.W. Polley. 1994. The CRP increases soil organic carbon. Journal of Soil and Water Conservation 49:488-492.

Grandy, A.S., and G.P. Robertson. 2006. Aggregation and organic matter protection following tillage of a previously uncultivated soil. Soil Science Society of America Journal 70:1398-1406.

Hargrave, Michael L., G. Oetelaar, N. Lopinot, B. Butler, and D. Billings. 1983. The Bridges Site: A late prehistoric settlement in the central Kaskaskia valley. Center for Archaeological Investigations Research Paper No. 39, Southern Illinois University, Carbondale.

Hargrave, Michael L., Charles R. McGimsey, Mark J. Wagner, Lee A. Newsome, Laura Ruggiero, Emanuel Breitburg, and Lynette Norr. 1998. The Yuchi Town Site (1RU63), Russell County, Alabama: An assessment of the impacts of looting. Report submitted to the Legacy Resource Management Program and Ft. Benning. Cultural Resources Research Center, USACERL Special Report 98/48. February, 1998.

Hayes, T.M., M.H.B., Hayes, and A.J., Simpson. 1999. Considerations of the amino nitrogen in humic substances. In: Managing Risks of Nitrates to Humans and the Environment, Edited by W.S. Wilson, et al. The Royal Society of Chemistry, Cambridge, UK. p. 206-227.

Hayes, T.M., B.E. Watt, M.H.B. Hayes, D. Scholefield, C.E. Clapp, R.S. Swift, and J.O. Skjemstad. 1997. Dissolved humic substances in waters from drained and undrained grazed grassland in SW England. In: Humic Substances, Peats, and Sludges. Health and Environmental Aspects. Edited by M.H.B. Hayes and W.S. Wilson, pp. 107-120. The Royal Society of Chemistry, Cambridge, UK.

Jefferies, Richard W., and Brian M. Butler. 1982. The Carrier Mills Archaeological Project: Human Adaptation in the Saline Valley, Illinois. Center for Archaeological Investigations, Research Paper 33. Southern Illinois University, Carbondale. 
Jobbagy, Esteban G., and Robert B. Jackson. 2000. The vertical distribution of soil organic carbon and its relation to climate and vegetation. Ecological Applications 10(2): 423-436.

Jobbagy, Esteban G., and Robert B. Jackson. 2001. The distribution of soil nutrients with depth: Global patterns and imprints of plants. Biogeochemistry 53:51-77.

Kabata-Pendias, A. 2001. Trace Elements in Plants and Soils. CRC Press, New York, New York.

Kissel, D.E. L.Sonon, P.F. Vendrell, and R.A. Isaac. 2009. Salt Concentration and Measurement of Soil pH. Communications in Soil Science and Plant Analysis 40: 179-187, 2009

Kissel, D.E., R.A. Isaac, R. Hitchcock, L.S. Sonon, and P.F. Vendrell, 2007. Implementation of Soil Lime Requirement by a Single-Addition Titration Method. Communications in Soil Science and Plant Analysis 38: 1341-1352.

Konrad, V.A., R. Bonnichsen, and V. Clay. 1983. Soil chemical identification of the thousand years of prehistoric human activity areas at the Munsungun Lake thoroughfare, Maine. Journal of Archeological Science 10:13-28.

Knoerl, J. J. and N. Versaggi. 1984. Plow zone sites: research strategies and management policy. American Archaeology 4:76-80.

Kreisa, P., and G. Walz. 1997. Archaeological Test Excavations of Four Sites at Fort Riley, Riley and Geary Counties, Kansas. Public Service Archaeological Research Program Research Report No. 29, University of Illinois at Urbana-Champaign.

Lewarch, Dennis E., and Michael J. O’Brien. 1981. Effect of short term tillage on aggregate provenience surface pattern. In Plow zone archaeology: Contributions to theory and technique, edited by M.J. O’Brien and D. E. Lewarch, pp.7-49. Vanderbilt University Publications in Anthropology 27.

Lindsay, W.L. 1972. Zinc in soils and plant nutrition. Advances in Agronomy 24:147186.

Mehlich, A. 1984. Mehlich-3 soil test extractant: A modification of Mehlich-2 extractant. Communications in Soil Science and Plant Analysis 15:1409-1416.

Mehlich, A. 1953. Determinations of P, Ca, Mg, K, Na, and NH4 by North Carolina soil testing laboratories. North Carolina State University, Raleigh, NC.

Meinke, C.W., S.T. Knick and D.A. Pyke. 2009. A Spatial Model to Prioritize Sagebrush Landscapes in the Intermountain West (U.S.A.) for Restoration. Restoration Ecology 17(5):652-659. 
Middleton, W.D. 2004. Identifying chemical activity residues on prehistoric house floors: A methodology and rationale for multi-elemental characterization of a mild acid extract of anthropogenic sediments. Archaeometry 46(1):47-65.

Middelton, W.D. and T.D. Price. 1996. Chemical anlaysis of modern and archeological house floors by means of inductively coupled plasma-atomic emission spectroscopy. Journal of Archeological Science 23:673-687.

Mukkerjee, A.B. 1998. Chromium in the environment. Science of the Total Environment. 217:9-19.

Olsen, S.R., and L.E., Sommers. 1982. Phosphorus. In: Methods of Soil Analysis. Part 2. 2nd ed. Agron. Monogr. 9. Edited by A.L. Page et al., pp. 403-430. ASA and SSSA, Madison, WI.

Ott, L. 1988. An Introduction to Statistical Methods and Data Analysis. PWS-Kent Publishing Company, Boston, Massachusetts.

Pollard, Mark, Catherine Batt, Ben Stern, and Suzanne M. M. Young. 2007. Analytical chemistry in archaeology. Cambridge University Press, Cambridge, UK.

Potter, K.N., H.A. Torbert, O.R. Jones, J.E. Matocha, J.E. Morrison, Jr., and P.W. Unger. 1998. Distribution and amount of soil organic carbon in long-term management systems in Texas. Soil Tillage Research 47:309-321.

Potter, K.N., H.A. Torbert, H.B. Johnson, and C.R. Tischler. 1999. Carbon storage after long-term grass establishment on degraded soils. Soil Science 164:718-725.

Prior, S.A., G.B. Runion, H.A. Torbert. And D.C. Erbach. 2004. A hydraulic coring system for soil-root studies. Agronomy Journal 96:1202-1205.

Querejeta, J.I., A. Roldan, J. Albaladejo, and V. Castillo. 2000. Soil physical properties and moisture content affected by site preparation in the afforestation of a semiarid rangeland. Soil Science Society of America Journal 64:2087-2096.

Reicosky, D.C., W.A. Dugas, and H.A. Torbert. 1997. Tillage-induced soil carbon dioxide loss from different cropping systems. Soil Tillage Research 41:105-118.

Richardson, L., and M.L. Hargrave. 1998. An Assessment of Impacts to Prehistoric Archaeological Sites, Fort Riley, Kansas. Report submitted to the Fort Riley Directorate of Environment and Safety. Cultural Resources Research Center, U.S. Army Construction Engineering Research Lab, Champaign, Illinois

Sanchez, A., M.L. Canbate, and R. Lizcano. 1996. Phosphorous analysis at archaeological sites: An optimization of the method and interpretation of the results. Archaeometry 38 pp. 151-64. 
Schiffer, M. B. 1983. Toward the identification of formation processes. American Antiquity 48:675-706.

Schiffer, M. B. 1987. Formation processes of the archaeological record. University of New Mexico Press, Albuquerque.

Schlezinger, D.R., and B.L. Howes. 2000. Organic phosphorous and elemental ratios as indicators of prehistoric human occupation. Journal of Archaeological Science 27:479-92.

Singer, M.J. and D.N. Munns. 1987. Soils: An Introduction. Macmillan Publishing Co., Inc. New York

Swift, R.S. 1996. Organic matter characterization. In: Methods of Soil Analysis, Part 3: Chemical Methods, pp.1011-1069, D.L. Sparks (ed.). Soil Science Society of America Book Series No. 5, Madison, Wisconsin.

Torbert H.A., S.A. Prior, and G.B. Runion. 2004. Impact of the return to cultivation on C sequestration. Journal of Soil and Water Conservation 59:1-8.

United States Department of Agriculture-Natural Resources Conservation Service. 2009. National Soil Survey Center, Lincoln, Nebraska.

Uren, N.C. 1992. Forms, reactions, and availability of nickel in soils. Advances in Agronomy 48:141-203.

Wildesen, L. E. 1982. The study of impacts on archaeological sites. In: Advances in archaeological method and theory, Vol. 5, pp. 51-96. Ed. M. B. Schiffer, Academic Press, New York.

Wood, W. R. and D.L. Johnson. 1978. A survey of disturbance processes in archaeological site formation. In: Advances in archaeological method and theory, Vol. 1, pp. 315-381. Edited by M. B. Schiffer, Academic Press, New York.

Zayed, A.M., and N. Terry. 2003. Chromium in the environment: Factors affecting biological remediation. Plant Soil 249:139-156. 